\title{
Professional development for providers of seasonal climate prediction
}

\author{
Peter J. Lamb*, Reed P. Timmer, M. Issa Lélé \\ Cooperative Institute for Mesoscale Meteorological Studies and School of Meteorology, The University of Oklahoma, \\ 120 D. L. Boren Blvd., Norman, Oklahoma 73072, USA
}

\begin{abstract}
Provision of seasonal climate predictions is envisioned to be a major component of the intended expansion of climate services. This paper focuses on the research basis for seasonal climate prediction, with emphasis on the needed broad professional development. Use is made of a 3-step interdisciplinary framework that previously was proposed to maximize the societal value of seasonal climate prediction schemes. Those steps involve: (1) identification of the human activities most impacted by climate variability, (2) determination of how affected regional economies can adjust or change to capitalize on the availability of skillful climate predictions, and (3) use of results from the required interdisciplinary research to develop climate prediction schemes that have maximum societal value. Consideration of these steps stresses the need for daily meteorological data and appropriate sets of 'impacts' data (e.g. for agriculture, water resources, public health, energy), the importance of conceptualizing and modeling the management decisions involved in those sectors (especially coupling of economic and biological/physical process models), and the necessity for the climate research community to initiate and sustain collaboration with specialists from these other scientific areas. The strong El Niño control on US winter precipitation illustrates the potential for such impact-related guidance to maximize seasonal climate prediction value. This theme is developed further by emphasizing methodologies and re-assessing results for 2 recent strongly contrasting climate research projects, which documented the influence of (1) winter temperature on US residential natural gas consumption and (2) the Intertropical Front (ITF) latitude on rainfall in the West African Sudan-Sahel zone. For each of these regional climate situations, the above 3-step framework is used to assess the seasonal prediction potential and associated professional development needs.
\end{abstract}

KEY WORDS: Seasonal climate prediction - Professional development - Daily meteorological data • Impacts data $\cdot$ Interdisciplinary modeling

- Resale or republication not permitted without written consent of the publisher

\section{INTRODUCTION}

A notable emerging trend in science applications worldwide is an increasing emphasis on the need to provide 'climate services'. This development is characteristic of individual countries and international organizations, and is viewed to hold considerable potential benefit for society.

In the USA, the National Oceanic and Atmospheric Administration (NOAA) recently proposed to reorganize itself explicitly to produce a 'NOAA Climate Service' as a new line office. When announcing this decision in February 2010, NOAA's justification was as follows: 'Individuals and decision-makers across widely diverse sectors - from agriculture to energy to transportation-are increasingly asking NOAA for information about climate change in order to make the best choices for their families, communities and businesses. To meet the rising tide of these requests, this newly proposed line office would be dedicated to bringing together the agency's strong climate science and service delivery capabilities' (www.noaa.gov/ climate.html).

Earlier, in September 2009, the Secretary of the US Department of the Interior (Ken Salazar) issued a Secretarial Order to establish 'a Department-wide approach for applying scientific tools to increase understanding of climate change and to coordinate an 
effective response to its impacts on tribes and on the land, water, ocean, fish and wildlife, and cultural heritage resources that the Department manages' (www. doi.gov/archive/climatechange/SecOrder3289.pdf). The resulting climate change research and adaptation activities will occur through programs of the Bureau of Reclamation, US Fish and Wildlife Service, and US Geological Survey, including a new Climate Change Response Council, 8 regional Response Centers, and a network of Landscape Conservation Cooperatives (www.doi.gov/news/pressreleases/Salazar-LaunchesDOI-Climate-Change-Response-Strategy.cfm; www. climatesciencewatch.org/index.php/csw/details/interior_ secretary_salazar_climate_initiative/).

Presumably, the above use of the term 'climate change' by NOAA and the US Department of the Interior includes climate variability on timescales of less than a decade, especially the societally all-important intraseasonal-to-seasonal-to-interannual range. This interpretation will need to prevail for society to receive immediate and near-term benefits from the envisioned climate services, and to prevent the initiative from being embroiled in (and even derailed by) the increasing political polarization of the longer-term climate change issue.

The much-needed short-term component of climate services has been recognized explicitly at the international level. Under the auspices of the World Meteorological Organization (WMO), the World Climate Conference-3 (WCC-3, Geneva, August 31 to September 4, 2009) focused on 'how humankind can benefit from the huge advances in climate prediction and information to establish services enabling decision-makers to better manage the risks related to current climate variability and imminent climate change'. The theme of WCC-3 was 'Climate prediction and information for decisionmaking', which included 'providing direction in tackling climate-related risks, such as droughts, floods, heat waves, famine and outbreaks of certain diseases, which affect the availability of essential social needs such as food, water and energy' (WMO 2009, p. 3). The major outcome of WCC-3 was agreement to establish a 'Global Framework for Climate Services' .

The above NOAA, US Department of the Interior, and WMO statements suggest that this important new development will have (or needs to have) 2 strong characteristics. First, the resulting climate services must be firmly based on the most important findings of recent and ongoing climate system research. It is essential that the 'climate science' ingredient stressed by the 2 US organizations has this strong climate system research component. Second, the provision of seasonal climate predictions is envisioned to be a major component of climate services. The necessity for this comprehensive approach has been strongly endorsed by the National Academy of Public Administration (2010) in the USA. It recommended that the proposed NOAA Climate Service has cutting-edge research and modeling capabilities in several laboratories (Physical Sciences, Chemical Sciences, Geophysical Fluid Dynamics) and issues seasonal predictions (through the Climate Prediction Center), and that it contains divisions that deal with observations, data stewardship, and service design and delivery.

The present paper therefore focuses on the research basis for seasonal climate prediction, with an orientation towards the broad 'professional-development' that will be needed at the national, regional, and multinational levels to achieve the desired goals and sustain the climate services initiative. To develop the line of reasoning presented, the present paper ultimately emphasizes methodologies and re-assesses results from 2 recent pieces of strongly contrasting climate research. Before that, however, emphasis is placed on the broader and highly demanding interdisciplinary nature of the challenge. The latter involves quantifying the beneficial/adverse societal impacts of climate variability that seasonal predictions have the potential to enhance/reduce, and identifying management strategies that accordingly can exploit skillful seasonal predictions.

\section{FRAMEWORK FOR SEASONAL CLIMATE PREDICTION DEVELOPMENT}

The framework adopted here for the development of seasonal climate predictions is an expansion of that originally proposed by Lamb (1981). It was used in subsequent agricultural applications, first for the USA and later incorporating other major producing nations, that continue to the present (e.g. Sonka et al. 1982, Sonka \& Lamb 1987, Mjelde et al. 1988, 1993, 1997, Mazzocco et al. 1992, Hill et al. 1999, 2004, Sherrick et al. 2000, Rubas et al. 2008, Timmer unpubl.). The framework also was endorsed and adopted by Hansen (2002).

In Lamb (1981), it was argued that 3 demanding and reasonably sequential prerequisites must be satisfied for seasonal climate prediction schemes to have maximum societal value. Those prerequisites are: (1) identification of the human activities most impacted by climate variability, (2) determination of how affected regional economies can adjust or change to capitalize on the availability of skillful climate predictions, and (3) use of results from the foregoing interdisciplinary research to focus development of climate prediction schemes that have the greatest societal value. This approach is also proposed and used here as a template to guide and assess professional development for seasonal climate prediction. 


\subsection{Identification of impacts of climate variability}

The first requirement is the identification of the human activities most impacted by intraseasonal-toseasonal-to-interannual climate variability, by geographical region, season (or part thereof), and weather parameter(s) responsible. Satisfaction of this prerequisite requires the development and availability of socalled 'impacts' data sets. Such data sets quantify key aspects of societal activity (e.g. agricultural production, water resource levels, human disease incidence and transmission, energy consumption) and hence reflect the impacts of intraseasonal-to-seasonal-to-interannual climate variability. Rigorous identification of those societal impacts requires the joint statistical analysis of the impacts data sets with climate data sets of the appropriate temporal and spatial resolutions. To capture the weather conditions that affect plant growth, water levels, disease transmission, and energy consumption, the climate data sets must have at least daily resolution.

The major professional-development challenge for this first prerequisite is appreciation of the need for and competence in the development of these essential and very diverse data sets. This requires that the National Meteorological and Hydrological Services (NMHSs) that constitute the WMO develop their own maximum quality climate and (probably more limited) water data sets and, consistent with WMO Resolution 40, make them available to the international community for the types of analysis advocated in the preceding paragraph. When adopting Resolution 40 in June 1995, the '(WMO) Congress stressed that WMO was committing itself to broadening and enhancing the free and unrestricted international exchange of meteorological and related data and products. The new practice states that ... Members should provide to the research and education communities, for their non-commercial activities, free and unrestricted access to all data and products exchanged under the auspices of WMO ...' (WMO 1996, p. 5). Clearly, this WMO policy recognizes that individual nations can benefit greatly from meteorological and interdisciplinary research that uses their data, even if some (or most) of that research is conducted in other countries.

Equally important, the WMO and its NMHSs have the responsibility to encourage and collaborate with their respective United Nations and national agency counterparts to attempt to satisfy the need for the impacts data sets. Without such data sets, it will not be possible to focus seasonal climate prediction development on the regions, seasons, and economic activities for which they can have the greatest potential benefit. This is a formidable challenge that falls at least partly in the broad professional-development domain, since it will require appreciation for and advocacy of the above opportunity provided by the WMO Resolution 40. Even in developed countries the availability of such data sets can be uneven, as is illustrated in Section 3.2 below. For less-developed nations, such data sets likely are relatively few in number and have proved difficult to construct. For example, the development of the most comprehensive possible agricultural production data set for central West Africa (Côte d'Ivoire, Burkina Faso, Mali) extended over 2 yr, required timeconsuming government approvals, involved multiple visits to agencies in each country and to the regional AGRHYMET Centre in neighboring Niger, revealed substantial inconsistencies and gaps in the data, and ultimately served to introduce those countries to key aspects (especially weaknesses) of one of their most important databases (Dibi Kanagh 2010).

\subsection{Determination of regional economic adjustments to climate variability}

The second prerequisite for seasonal climate predictions to have maximum societal value involves the determination of how regional economies that are impacted strongly by intraseasonal-to-seasonal-tointerannual climate variability can adjust or change to capitalize on the availability of skillful predictions.

Satisfaction of this prerequisite begins with the comprehensive conceptualizing of the management decisions that are involved in (for example) producing a crop, operating a multipurpose dam, curtailing transmission of a disease, or ensuring an adequate energy supply. Those decisions should have the potential to modulate the societal effects of climate variability. For example, the major decisions for unirrigated crop production involve the following: selection of crop and variety (maturity length, drought resistance) to plant, performance of tillage practices, timing of planting, spatial density of seeding, frequency and intensity of fertilizer applications, use of chemical or other treatments to suppress weeds and insect pests, and timing and method of harvest (e.g. Sonka et al. 1982, 1987, Mjelde et al. 1988, 1997). This same general decision suite is applicable to the production of Moroccan wheat, Malian millet, or Iowa maize, although the available options clearly are a function of the sophistication of the agricultural system. Counterpart decision suites can be developed for the water resources, public health, and energy sectors.

Such conceptualization provides the basis for the necessary development and integration of (1) economic models and (2) biological and physical process models. This modeling framework is illustrated in Fig. 1, where a key characteristic is the embedding of the process model within the economic model. While the eco- 
GENERALIZED MODELING FRAMEWORK

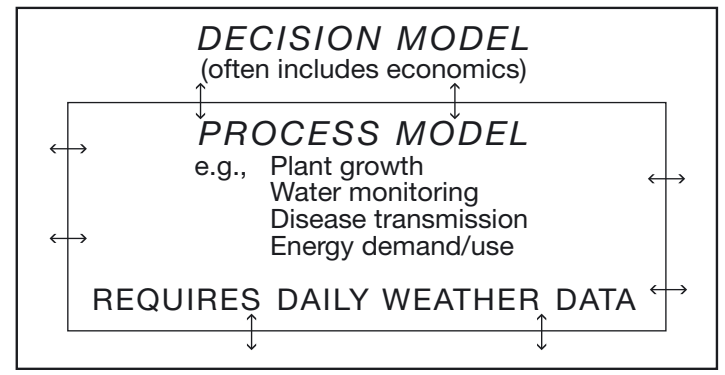

(Current year's planning)

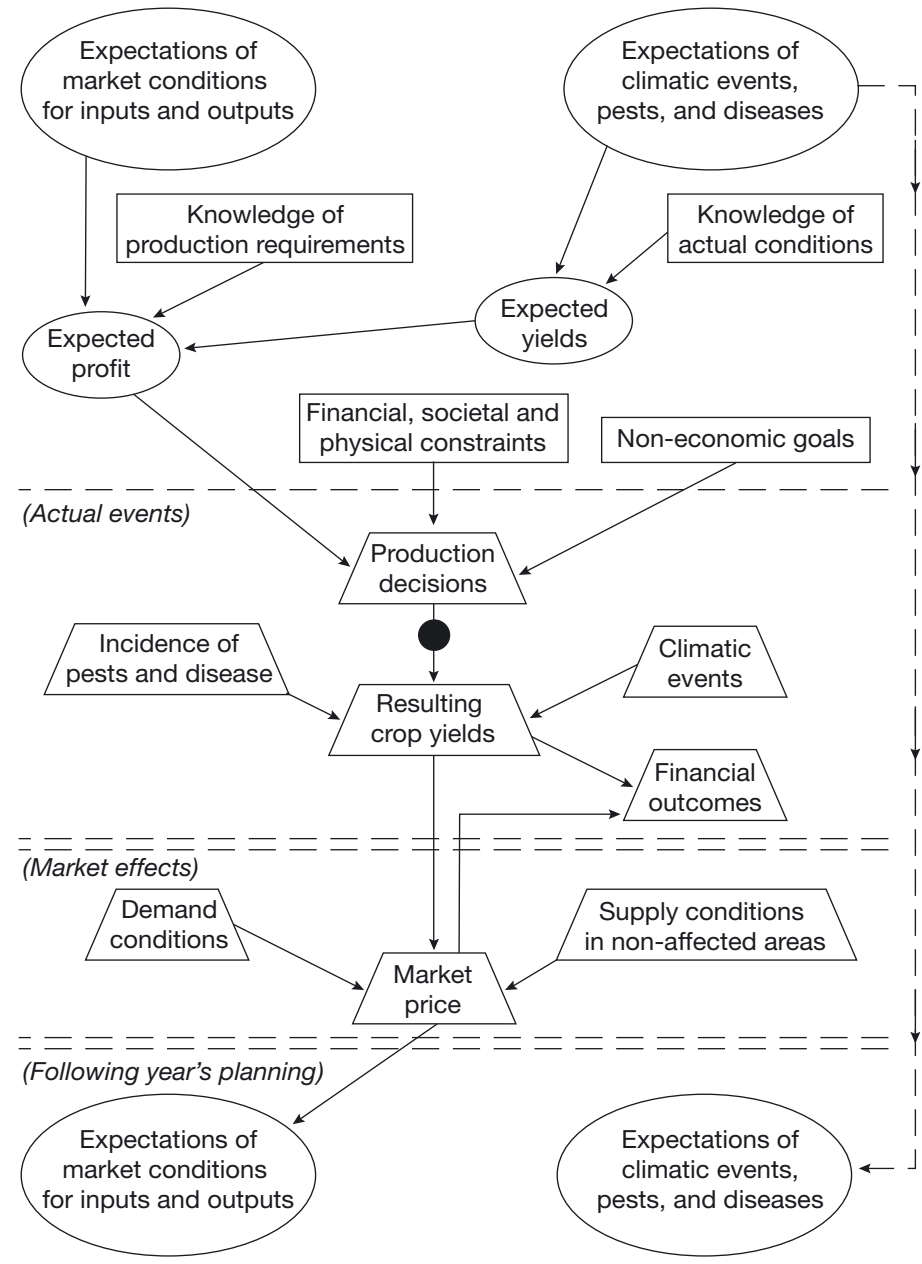

Fig. 1. Upper panel: schematic illustration of integrated modeling framework needed for seasonal climate prediction design and value estimation. Lower panel: an example of a fuller decision-making context (for central US maize/soybean production) that is represented by the outer box in the upper panel. Lower panel factors enclosed by: ovals, are uncertain expectations; rectangles, are known at the time the decision is made; trapezia, occur during or are the results of the production process. The embedded plant growth process model would be situated in the very center ( of the decision-making representation. Thus, the plant modeling reflects both prior influences and subsequent economic conditions and management decisions. Lower panel is modified from Sonka \& Lamb (1987) and Sherrick et al. (2000) nomic model represents management decisions of the type listed in the previous paragraph, it must be coupled (2-way) to a process model that adequately reflects the biology and/or physics of the societal activity involved. Such a process model can (for example) suggest growing a plant in a manner that reflects not only the management decisions employed, but also how the effects of those management decisions are impacted by the growing season climate that occurs. Further, the management decisions made can be influenced by the availability of seasonal climate predictions. For instance, successful anticipation of abundant growing-season rainfall can enhance crop production through increased inputs (seeding density, fertilizer and pesticide applications). Conversely, such inputs need to be substantially reduced to optimize production in seasons of deficient rainfall. These modeling attributes and capabilities are developed and illustrated in Sonka \& Lamb (1987), Mjelde et al. (1988), Mazzocco et al. (1992), Hill et al. (1999, 2004), and Rubas et al. (2008).

Use of such coupled modeling can quantify the relative economic benefits of lead-time versus accuracy for seasonal prediction schemes. While increased prediction lead-time enhances decision-maker flexibility that potentially can permit greater societal adjustment and increase profits, it also inevitably reduces prediction accuracy and so can diminish profits. This lead-time/ accuracy trade-off will be a key consideration for the use of seasonal climate predictions as a tool for regional economic adjustment to climate variability. Early treatments of this issue have included the highly contrasting agricultural systems of the central USA (Mjelde et al. 1988) and Burkina Faso (Ingram et al. 2002).

There also is a need to address the implicit prediction uncertainty and associated management issues more broadly in this coupled modeling context. Currently available prediction schemes always contain uncertainty-often via the use of probabilities (e.g. Mason \& Chidzambwa 2008, O'Lenic et al. 2008, Barnston et al. 2010) — which can be considerable. While improved climate system understanding is expected to reduce this uncertainty in some cases, such gains could be offset somewhat by the need to produce more specialized predictions tailored to specific societal activities, as advocated here. The guidance available for modeling these complex interactions is increasing, and extends from statistical analyses that established the desirability of probability-based prediction formats for northeast Brazil (Ward \& Folland 1991) to ethnographic interview results obtained in quest of 'convincing farmers (in the southeastern USA) that the (prediction) information offered is produced with their needs in mind' (Crane et al. 2010, p. 56). 
Just as for the first prerequisite above (Section 2.1), the fundamental professional development challenge for this second prerequisite is recognition of the interdisciplinary nature of the needed research and development. Construction of the required models (economic, biological, physical) must be performed by specialists in those areas who, particularly for developing nations, likely will have to be recruited from outside the usual circle of NMHS collaborators. While the quantitative skills required for this model development will be considerable, they will need to be matched by appreciation for the climate context within which the resulting models will function. Understanding of the climate context will, in particular, help shape the 2-way coupling of the economic and process models and so facilitate the treatment of uncertainty and risk management. Clearly, the climate community (including the NMHSs) has the responsibility to work with other specialists on these important matters.

It also is vital that the NMHSs understand that their daily data will be needed to 'force' the process models. This situation further reinforces the aforementioned need (see Section 2.1) for the NMHSs to develop and make available high-quality historical data sets with a daily resolution. Such historical data sets are required for model development, calibration, tuning, and coupling. Furthermore, for in-season monitoring of the climate and its impacts, the historical daily data sets must be complemented by access to real-time daily data on at least a weekly basis, using geographical information systems (GISs) of the type recently developed for West Africa by Tarhule et al. (2009). Clearly, the GIS community has much to contribute as well, and so its involvement is highly desirable.

\subsection{Development of seasonal prediction schemes with societal value}

Seasonal climate predictions will have maximum societal value if they focus on weather parameters of high potential socioeconomic impact in regions where the economic and social systems possess the flexibility to adjust or change in cognizance of the forecasts. Satisfaction of the 2 foregoing prerequisites (Sections 2.1 and 2.2) thus would provide optimum regional/ seasonal targets for climate prediction development. The principal professional-development challenge in this regard is for the climate research community to keep fully abreast of key developments in the interdisciplinary research areas that have implications for climate prediction design. For developing nations, there will be a need for collaboration between their NMHSs, which have important local understanding, with major outside (including multi-national) interdisciplinary and climate research groups and centers.
The lead-in to Section 2 stated that the 3 prerequisites were 'reasonably sequential', and their subsequent development has followed that pattern. However, this was a somewhat idealistic representation, because the climate research community has (and always will) proceed with seasonal prediction development in the absence of such interdisciplinary impactrelated guidance. Those efforts are driven by individual and group curiosity and organizational mandates, and capitalize on our growing understanding of the mechanisms of intraseasonal-to-seasonal-tointerannual climate variability. That there have been some notable accomplishments in this regard does not undermine the larger, interdisciplinary, sequential process advocated here. Instead, some of those successes emphasize the potential value of supporting research of the type proposed for the first 2 prerequisites (see Sections 2.1 and 2.2).

An instructive example is the control of US winter precipitation by tropical Pacific El Niño events. Substantial understanding of this association has occurred since the mid-1980s (e.g. Ropelewski \& Halpert 1986, 1987, Kiladis \& Diaz 1989, Livezey et al. 1997, Montroy 1997, Montroy et al. 1998, Livezey \& Timofeyeva 2008), as is illustrated in Fig. S1 in the Supplement at www.int-res.com/articles/suppl/cr047p057_supp.pdf. Two striking and highly contrasting anomalies dominate the monthly precipitation composites generated for 5 to 8 El Niño years between 1950 and 1992: aboveaverage precipitation bordering the Gulf of Mexico and extending up the Atlantic coast to Virginia and (for March) even further; and the opposite anomaly for a large interior region extending northward from the Tennessee Valley through the Great Lakes. That these anomalies were replicated very strongly during the El Niño events that included both early 1998 and early 2010 (Fig. S1 in the Supplement) substantiates further their strong predictability when the global climate system is in an El Niño mode. Furthermore, because of the well-known life cycle and longevity of El Niño (e.g. Rasmusson \& Carpenter 1982), this predictability has a 6 to 8 mo lead-time.

There is evidence that this lead-time was somewhat exploited in the USA, at least for general planning purposes, during the strong and well-publicized 1997-1998 El Niño (e.g. Ross et al. 1998, Changnon 2000). The substantial intensity and notoriety of that El Niño likely contributed to this adaptation, which apparently was less (much less?) characteristic of the more average and under-publicized 2009-2010 El Niño. Thus, a crucial professional-development issue is whether this substantial El Niño-based seasonal prediction capability for US winter precipitation is being utilized fully for society. Clearer delineation and fuller realization of this considerable potential 
would result from impact-related guidance provided by interdisciplinary research of the type advocated to satisfy the first 2 prerequisites above (Sections 2.1 and 2.2).

We next develop this theme further by emphasizing the methodologies and re-assessing the results for 2 recent pieces of strongly contrasting climate research. Those studies focused on opposite ends of the global continuum of socioeconomic development.

\section{TEMPERATURE CONTROL ON USA RESIDENTIAL NATURAL GAS CONSUMPTION}

\subsection{Data and analysis}

This quantification of the effects of temperature on gas consumption used sets of daily meteorological data and an appropriate impacts data set.

The impacts data set contained state-level monthly residential gas consumption totals for the period January 1989 to December 2000 for all US states east of the Rocky Mountains. Consumption data for earlier years were not used because they were available only on a national basis and also reflected regulation-related, non-weather influences on gas prices and consumption. These monthly state-level totals were aggregated

\subsection{Background}

Natural gas is a major energy source for residential heating in the USA east of the Rocky Mountains, especially in the central region between the Rockies and the Appalachian Mountains (www.aga.org). To supply the winter gas demand, during preceding months gas is pumped northward in pipelines from its principal US source in Texas-Louisiana-Oklahoma and stored in underground rock formations (www.eia. doe.gov/pub/oil_gas/natural_gas/analysis_ publications/ngpipeline/ngpipelines_map. html). Since the gas demand for residential heating is negatively related to winter temperature, seasonal predictions have the potential to influence the pre-season gas transport to and storage in major consumption regions. If the pre-season gas storage does not meet the winter demand, distribution companies have to acquire further supplies at possibly increased cost during that season (Lamb \& Changnon 1981).

Thus, one important component of seasonal climate prediction development for the US gas industry is quantifying the effects of temperature on residential gas consumption. This involves addressing the first prerequisite (Section 2.1) in the above framework for climate prediction development, i.e. the identification of the impacts of climate variability. To do this, we draw on the recent comprehensive investigation by Timmer \& Lamb (2007), where full details are available. Then, we assess those results in the context of the total seasonal prediction framework offered above, including from the professional-development standpoint.
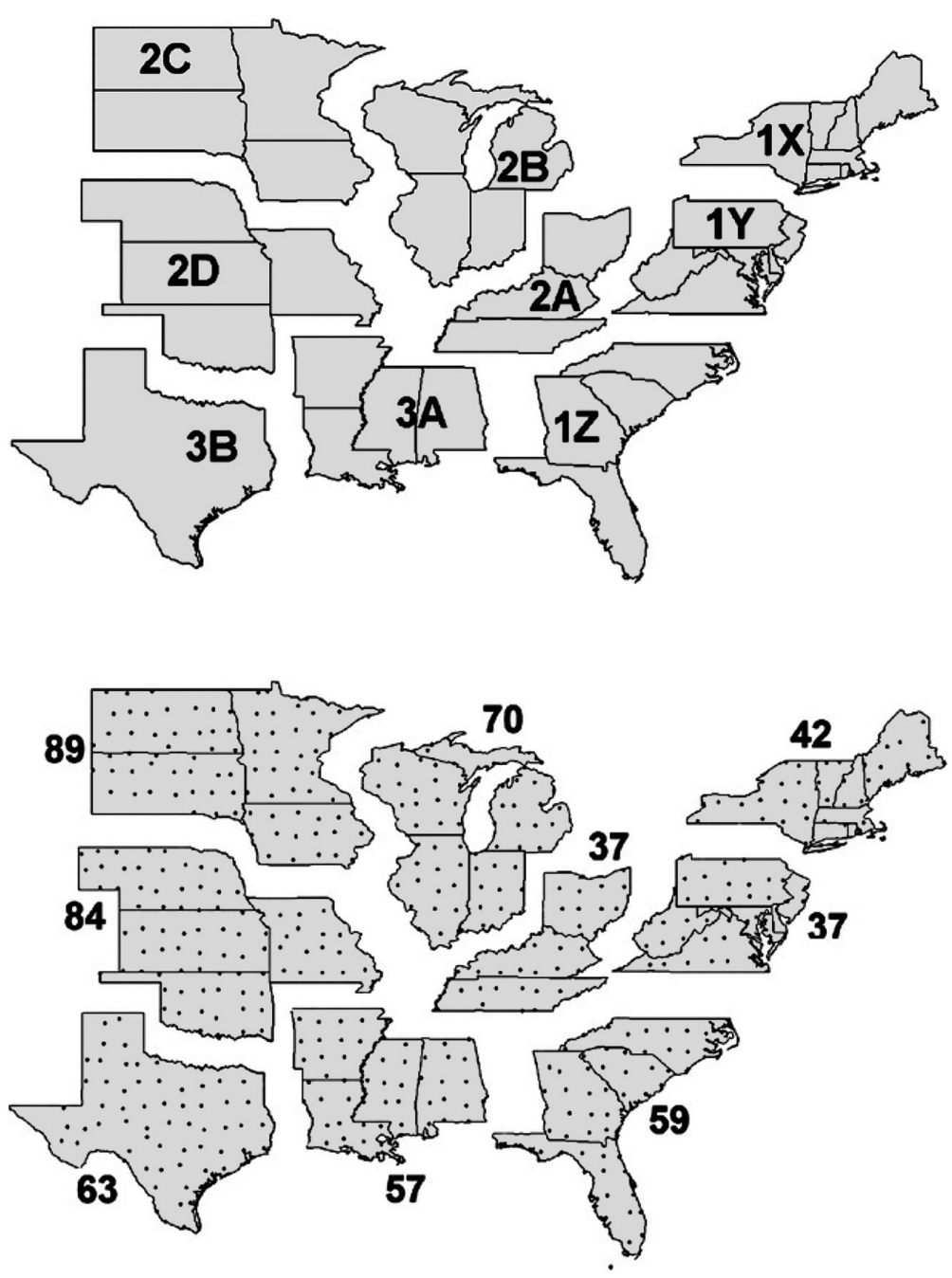

Fig. 2. Petroleum Administration for Defense Districts (PADDs) for which days below (selected) percentiles (DBP) and heating degree days (HDD) indices are calculated and regressed against residential natural gas consumption. Top panel: definitions and names of PADDs. Lower panel: locations of Richman-Lamb temperature stations $(\bullet)$ in each PADD, with adjacent number giving total number of stations in each PADD. From Timmer \& Lamb (2007) 
across the Petroleum Administration for Defense Districts (PADDs) shown in Fig. 2 (top panel), to provide the impacts input for the joint climate-impacts statistical analysis summarized below (the remainder of this section, and Section 3.3).

Because of the day-to-day extremes of US winter temperature variability, the temperature indices involved in that joint statistical analysis were of the required fine resolution: 'heating degree days' (HDDs) and 'days below (selected) percentiles' (DBP). Clearly, daily temperature data were required to evaluate these indices. Such data were obtained from the RichmanLamb sets of fine-resolution daily maximum and minimum temperatures for North America east of the Rocky Mountains from 1949 to 2000 (Skinner et al. 1999, Timmer \& Lamb 2007). When this research was performed in the early-to-mid-2000s, those data sets had not been extended beyond 2000. Hence, the joint climateimpacts statistical analysis involved was limited to the period 1989 to 2000. Fig. 2 (lower panel) indicates the location and number of the temperature stations used to generate the HDDs and DBPs for each PADD.
The joint climate-impacts statistical analysis performed used 1989-2000 time series for each PADD of monthly and seasonal (1) residential gas consumption totals and (2) area-averaged HDD and DBP values calculated separately using daily maximum, minimum, and mean temperatures. This treatment used full ranges of thresholds for $\mathrm{HDD}\left(0\right.$ to $40^{\circ} \mathrm{C}$, at $2^{\circ} \mathrm{C}$ intervals) and DBP (2nd to 80th percentile, at 2-percentile intervals) quantification. The historical temperature percentiles were determined from the entire 19492000 daily data sets. Linear correlation and regression analysis was used to identify which temperature-based indices were most strongly related to residential gas consumption on several timescales, and establish the strength of those dependencies.

\subsection{Diagnostic results}

Fig. 3 documents the strength of temperature control on gas consumption using monthly and seasonal timescales. It reveals some important timescale differences. a) DBP

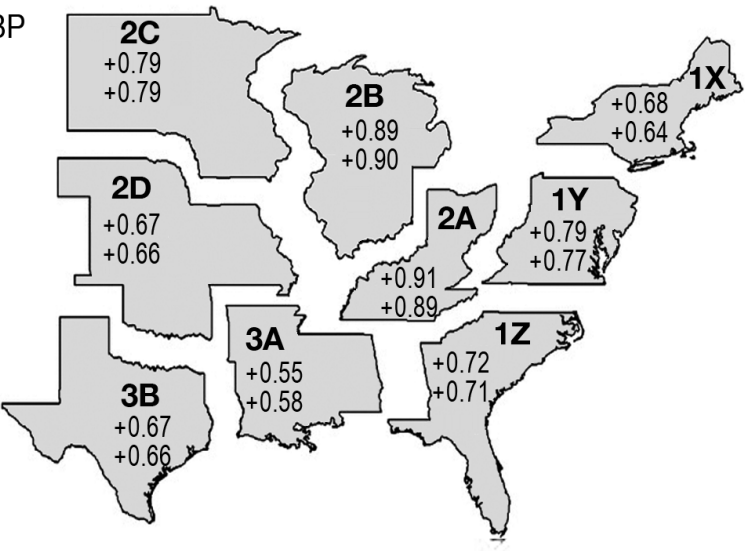

b) HDD

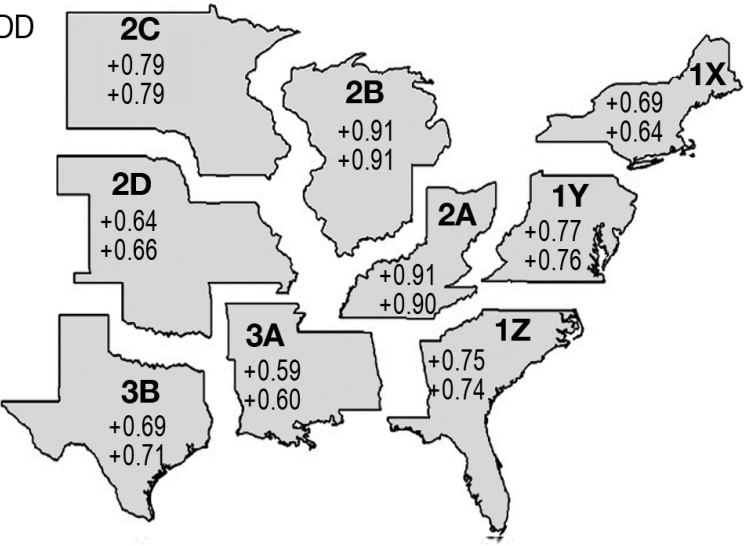

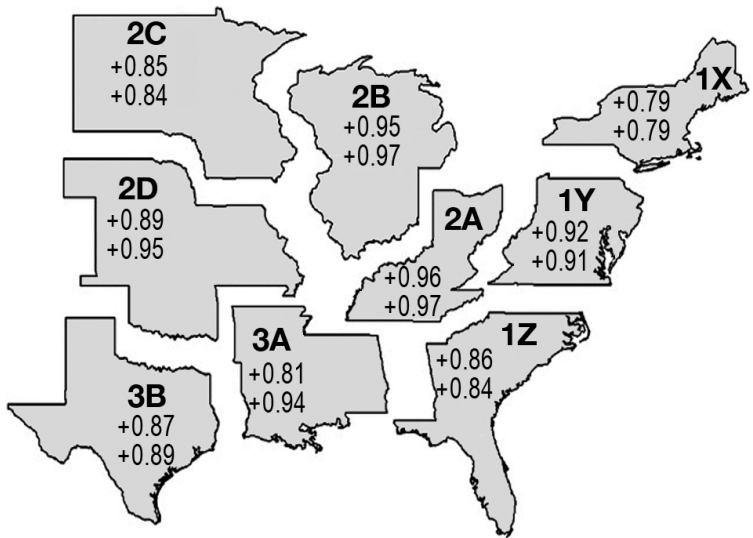

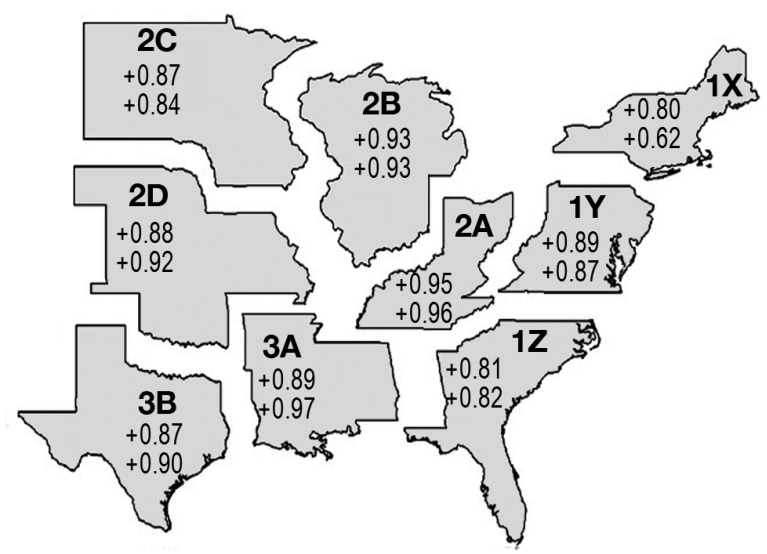

Fig. 3. Maximum monthly (left panels) and seasonal (right panels) correlations with residential natural gas consumption of (a) days below (selected) percentiles (DBP) indices and (b) heating degree days (HDD) indices for each Petroleum Administration for Defense District (PADD) for 3 mo (first number below PADD name) and 4 mo (second number below PADD name) winters during 1989-2000. Correlation thresholds for a $5 \%$ statistical significance level are +0.28 for monthly indices for 3 mo winters, +0.24 for monthly indices for 4 mo winters, and +0.50 for seasonal indices for 3 and 4 mo winters, and for a $1 \%$ significance level are +0.39 , +0.33 , and +0.66 , respectively, according to a 1-tailed $t$-test (Wilks 2006, p. 131-140). From Timmer \& Lamb (2007) 
Pronounced spatial contrasts are evident on the monthly timescale, with essentially the same results being given by the optimum DBP and HDD indices (Fig. 3, left panels). The maximum gas consumption-temperature index correlations are very high for the 2 northcentral PADDs $\left(2 \mathrm{~B}, 2 \mathrm{~A}_{i}+0.89\right.$ to +0.91$)$. The importance of this finding is underlined by the fact that one-third of the total US residential natural-gas consumption occurs in these PADDs. This gas consumption-temperature relationship weakens in all directions away from the north-central region, especially immediately to the south into the south-central PADD $\left(3 \mathrm{~A}_{i}+0.55\right.$ to +0.60$)$. However, gas consumption in PADD 3A is a mere $3.7 \%$ of the national total. These very low monthly correlations for PADD 3A, and smaller reductions for the 2 adjacent extreme southern PADDs (3B, 1Z), stemmed from especially weak correlations in January and (less so) February (e.g. +0.33 and +0.54 for PADD 3A). It was speculated that this diminished mid-winter gas consumption-temperature association across the extreme southern USA was due to societal characteristics there, e.g. high human sensitivity to 'cold' in otherwise warmto-hot climates, coupled with inferior home insulation relative to further north.

A substantial weakening of the monthly gas consumption-temperature correlation from its north-central maximum also occurs eastward/northeastward into New England (PADD 1X +0.64 to +0.69), despite that region having lengthy and cold winters and spanning the same latitude range as the northern half of north-central PADD 2B (Fig. 3, left panels). This decrease was attributed to larger-scale economic conditions that greatly reduce the dependency on natural gas for home heating in New England. Specifically, homes in the northern, more rural, less populated, and colder areas of PADD 1X are heated primarily with fuel oil, whereas homes in the southern, more urban, highly populated, and warmer areas of the PADD more often are heated with natural gas. Despite this situation, PADD $1 \mathrm{X}$ accounts for $11 \%$ of US residential gas consumption.

These spatial contrasts were reduced greatly, or even removed, when the analysis was repeated with the gas consumption, HDD, and DBP totals aggregated to the seasonal timescale (Fig. 3, right panels). For the north-central $(2 \mathrm{~B}, 2 \mathrm{~A})$ and northwestern (2C) PADDs, the correlation increases from the monthly to seasonal timescale (only 0.02 to 0.08 ) were constrained to be small by the already high monthly correlations there. In contrast, much larger correlation increases characterized the Central Great Plains (PADD 2D; 0.24 to $0.29)$ and the western $\left(3 B_{;} 0.18\right.$ to 0.21$)$ and especially central $\left(3 \mathrm{~A}_{;} 0.26\right.$ to 0.37$)$ southern-tier PADDs. For these PADDs, the seasonal aggregation reduced the impact of the low January correlations, particularly for PADD 3A for which the explained variance increased from 30 to $36 \%$ (monthly) to 66 to $94 \%$ (seasonal) and surprisingly approached that obtained for the northcentral PADDs. Inclusion of November in the winter season maximized that increase. The seasonal aggregation also strengthens most of the gas consumptiontemperature index correlations for New England (PADD 1X), but not to the level of the north-central PADDs.

\subsection{Seasonal prediction implications}

As demonstrated in Table 1, the above diagnostic results (Section 3.3) yield regression equations that predict with remarkably high accuracy the winter residential natural-gas consumption as a function of the contemporaneous winter temperature. On the monthly timescale, that high accuracy characterizes only the

Table 1. Seasonal regression equations and associated correlation coefficients (r) that express residential natural gas consumption ( $\mathrm{NG}_{\text {; }}$ millions of cubic feet, Mmcf) as functions of days below (selected) percentiles (DBP) and heating degree days (HDD) indices based on daily mean temperature for 3 mo (December to February) winters for each Petroleum Administration for Defense District (PADD, see Figs. $2 \& 3$ ) for 1989-2000. A correlation of +0.28 is significant at the $5 \%$ statistical significance level and +0.39 is significant at the $1 \%$ level according to a 1-tailed $t$-test (Wilks 2006, p. 131-140). From Timmer \& Lamb (2007)

\begin{tabular}{|c|c|c|c|c|c|}
\hline \multirow[t]{2}{*}{ PADD } & \multirow[t]{2}{*}{ Region } & \multicolumn{2}{|c|}{$\longrightarrow$ DBP indices } & \multicolumn{2}{|l|}{$\longrightarrow$ HDD indices } \\
\hline & & Equation & $\mathrm{r}$ & Equation & $\mathrm{r}$ \\
\hline $1 \mathrm{X}$ & New England & $\mathrm{NG}=230590.1+592.2(\mathrm{DBP})$ & 0.79 & $\mathrm{NG}=229721.3+516.2(\mathrm{HDD})$ & 0.78 \\
\hline $1 \mathrm{Y}$ & Mid-Atlantic & $\mathrm{NG}=279205.3+1146.7$ (DBP) & 0.87 & $\mathrm{NG}=283647.0+1072.5(\mathrm{HDD})$ & 0.85 \\
\hline $1 \mathrm{Z}$ & Southeastern USA & $\mathrm{NG}=68691.7+887.3$ (DBP) & 0.86 & $\mathrm{NG}=67973.7$ + 767.5 (HDD) & 0.79 \\
\hline $2 \mathrm{~A}$ & Ohio River Valley & $\mathrm{NG}=197446.6+1019.9(\mathrm{DBP})$ & 0.95 & $\mathrm{NG}=197056.8$ + 997.4 (HDD) & 0.94 \\
\hline 2B & Great Lakes region & $\mathrm{NG}=469461.5+1910.5$ (DBP) & 0.93 & $\mathrm{NG}=474397.9+1801.3(\mathrm{HDD})$ & 0.91 \\
\hline $2 \mathrm{C}$ & Northern Great Plains & $\mathrm{NG}=96664.2+327.4$ (DBP) & 0.82 & $\mathrm{NG}=97834.7+321.1$ (HDD) & 0.82 \\
\hline $2 \mathrm{D}$ & Central Great Plains & $\mathrm{NG}=137475.4+625.4$ (DBP) & 0.89 & $\mathrm{NG}=137310.6+666.1$ (HDD) & 0.88 \\
\hline $3 \mathrm{~A}$ & $\begin{array}{l}\text { Central Gulf Coast } \\
\text { and Arkansas }\end{array}$ & $\mathrm{NG}=69232.5$ + 504.9 (DBP) & 0.79 & $\mathrm{NG}=54702.4+708.5$ (HDD) & 0.89 \\
\hline 3B & Texas & $\mathrm{NG}=106980.0+513.2(\mathrm{DBP})$ & 0.86 & $\mathrm{NG}=103723.2+563.9(\mathrm{HDD})$ & 0.87 \\
\hline
\end{tabular}


most important region for gas consumption (northcentral). However, the high accuracy extends across much of the study region when the gas consumption and temperature index values are aggregated across the entire season. This situation thus holds considerable potential for winter temperature predictions to be incorporated into the management strategies of the natural gas supply industry - provided, of course, such predictions are of sufficient accuracy.

Recent research offers some encouragement in that regard on the seasonal timescale. Livezey (1990) assessed the skill of the US National Weather Service's (NWS) zero-lead, categorical winter seasonal temperature predictions (above, near, and below normal) for 38 yr preceding the 1989-2000 period for which our gas consumption-temperature relations were obtained. Most importantly, the areas of relatively high predictive skill identified, especially for the 2 extreme temperature categories, included some regions for which the above contemporary gas consumption-temperature relations were very strong (Wisconsin and Illinois, western PADD 2B; Kentucky and Tennessee, southern PADD 2A) or moderately so (the Carolinas, northern PADD 1Z; Minnesota and eastern North Dakota, northeastern PADD 2C). Livezey (1990) conversely found low temperature predictability for the New England region that the above research (Section 3.3) identified to have weaker gas consumption-temperature relations.

A recent retrospective assessment of NWS long-lead winter temperature predictions since 1995 (Livezey \& Timofeyeva 2008) provided further confirmation of and insight into the above results. Additional evidence was presented of relatively high predictive skill for the north-central US regions. Also shown, very strikingly, is the strong dependence of this predictive skill on the occurrence of moderate-to-strong El Niño or La Niña (El Niño Southern Oscillation [ENSO]) events. Furthermore, the high ENSO-based predictive skill is sustained for lead-times extending out to $8.5 \mathrm{mo}$.

This spatial coincidence of very strong gas consumption-temperature relationships with encouraging winter temperature predictive skill for PADDs $2 \mathrm{~B}, 2 \mathrm{~A}, 1 \mathrm{Z}$ and $2 \mathrm{C}$ suggests that the regression equations developed here could be used effectively for the real-time prediction of gas consumption for those areas. However, the desired coupling of these regression equations with the probabilistic categorical NWS prediction format (O'Lenic et al. 2008) would require an additional development effort. This 'transition to operations' would need to be underpinned by statistical analysis of historical temperature data designed to translate the probabilistic categorical NWS winter temperature prediction format into appropriate ranges of DBP and HDD values that could be used in an ensemble-type prediction approach.

\subsection{Professional-development context and assessment}

This section assesses the above research and development (Sections 3.1 to 3.4 ) and its potential applications in the context of the professional-development framework proposed for seasonal climate prediction at the start of Section 2. That framework argued for 3 demanding and reasonably sequential prerequisites to be satisfied before seasonal climate predictions could have maximum societal value.

The first prerequisite (Section 2.1) clearly was satisfied fully, since a human activity of considerable economic importance (US residential natural gas consumption) indeed was shown to be strongly impacted by climate variability (winter temperature), with appropriate regional and seasonal definition. Establishment of this relationship was made possible by the availability of appropriate sets of impacts data (monthly gas totals) and daily meteorological data (maximum and minimum temperatures). However, even for the most economically developed nation in the world, the joint statistical analysis of these data sets that quantified their association was limited to a 12 yr (1989 to 2000) period. This situation resulted from the earlier/later unavailability of the necessary impacts/climate data, and emphasizes the non-trivial challenges involved in developing both types of essential data sets.

The second prerequisite (Section 2.2) advocated determination of how affected regional economies can adjust or change to capitalize on the availability of skillful climate predictions, as a key step to ensuring those predictions have maximum societal value. Management decision conceptualization and modeling was suggested to be most helpful. However, the effort described above was very minimal in these respects. It was limited to acknowledgement of the pre-season pipeline delivery and underground storage of the gas, and the desirability of that storage meeting the inseason demand that then was shown to be strongly temperature-related. The lack of further information concerning this prerequisite largely stems from all components of the US energy sector being completely privatized. Management decision conceptualization and modeling on the supply side are conducted within the companies on a proprietary basis. At least some of those companies employ meteorologists as well as economists, who have access to the Timmer \& Lamb (2007) paper on which this section is based and hence the opportunity to use it in the context advocated here. However, while we have received inquiries about that paper from outside of the USA, there has been no contact to date with any US gas supply company. In the USA, the need for professional development for seasonal climate prediction thus extends to the private sector. 
Concerning the third prerequisite (Section 2.3)using results of interdisciplinary research to focus climate prediction development-because of the proprietary constraints mentioned in the previous paragraph, the access of the NWS to relevant management decision conceptualization and modeling products likely is limited to those developed and disseminated in the public domain. Anyhow, the NWS is mandated only to produce generalized predictions on all timescales (e.g. O'Lenic et al. 2008), and must refrain from tailoring its products to particular economic activities because that role is reserved for private meteorological companies. This situation is in strong contrast to that now prevailing in some other countries, where NMHSs have commercial divisions (e.g. UK Met Office) that tailor products to private sector or other government agency needs after receiving the best guidance possible from those users. However, even given the relative weakness of such linkages in the USA, the complementarity of the results of the impacts analysis and the seasonal prediction skill assessment (Section 3.4) underscores the potential for US predictions to have maximum societal value concerning residential natural gas consumption.

\section{WEST AFRICAN INTERTROPICAL FRONT CONTROL ON SUDAN-SAHEL RAINFALL AND SOCIOECONOMIC ACTIVITY}

\subsection{Background}

The Intertropical Front (ITF) is a fundamental feature of the atmospheric circulation over West Africa. It separates the wedge of warm moist southwesterly monsoon flow off the tropical Atlantic from the much hotter and very dry northeasterly wind from the Sahara Desert. At the surface, the wind direction discontinuity is characterized by pronounced temperature and humidity gradients that migrate seasonally northward then southward, lagging somewhat the change in the zenith angle of the sun in the northern tropics. For the Sudan-Sahel zone (10 to $20^{\circ} \mathrm{N}$ ), the northward ITF advance occurs relatively slowly between early April and early August, with the southward retreat following more rapidly from mid-August until midNovember. The monsoon rainbelt follows this ITF migration, but remains a few hundred kilometers to the south where the monsoon wedge is thickest.

The ITF is considered important for not only the intraseasonal-to-seasonal-to-interannual rainfall variability of West Africa, but also for the incidence of the region's most serious and vector-borne infectious diseases (malaria, meningitis) and its desert locust plagues that can devastate crops and pastures. It is clear that meningitis outbreaks occur in the harsh, dry conditions north of the ITF and that malaria infections in individuals originate in the warm and moist environment south of the ITF. Furthermore, the equatorward ITF retreat occasionally is accompanied by a massive southward migration of desert locusts that breed near the ITF, especially in wetter years.

Thus, 2 important components of seasonal climate prediction development for the West African SudanSahel zone are (1) quantifying the role of the ITF latitude for rainfall and, if that relationship is sufficiently strong, (2) assessing the predictability of the seasonal ITF advance and retreat. The first of these components contributes to addressing the first prerequisite (Section 2.1) in the above framework for climate prediction development. The second of the above components would contribute to the third prerequisite (Section 2.3) in the framework, by focusing the development of climate prediction schemes to achieve maximum societal value. To address these issues, we draw on the recent comprehensive investigation by Lélé \& Lamb (2010), where full details are available. Subsequently, we assess the results in the context of the total seasonal prediction framework offered here, including from the professional-development standpoint.

\subsection{Data and analysis}

Three sets of daily meteorological data were used in this quantification of the effects of the ITF latitude on Sudan-Sahel rainfall, and the follow-up assessment of the predictability of the seasonal ITF advance and retreat and its implications for seasonal rainfall prediction.

The rainfall data set contained daily totals for the April-October period from 1974 to 2003 for 82 stations in the Sudan-Sahel zone $\left(10\right.$ to $\left.20^{\circ} \mathrm{N}\right)$ between $12^{\circ} \mathrm{W}$ and $24^{\circ} \mathrm{E}$ (Fig. 4). Most of these data were provided originally by the Directions de la Météorologie Nationales (DMNs) or NWSs of Mali, Burkina Faso, Ghana, Benin, Niger, and Chad. After extensive quality control of all available data (111 stations), the 82 stations selected had records that were the most complete and most reliable.

The surface position of the ITF was delineated on a daily basis by the $15^{\circ} \mathrm{C}$ dew-point temperature $\left(T_{\mathrm{d}}\right)$ isodrosotherm. Daily values of $T_{\mathrm{d}}$ were given by the standard US Advanced Weather Interactive Processing System (AWIPS) empirical algorithm. The daily vapor pressure inserted into the AWIPS $T_{\mathrm{d}}$ equation was obtained via standard thermodynamic relationships from the coincident (or nearly so) daily minimum temperature $\left(T_{\min }\right)$ and daily maximum relative humidity $\left(\mathrm{RH}_{\max }\right)$. The daily $T_{\min }$ and $\mathrm{RH}_{\max }$ data sets utilized were for the April-October period from 1974 to 2003 


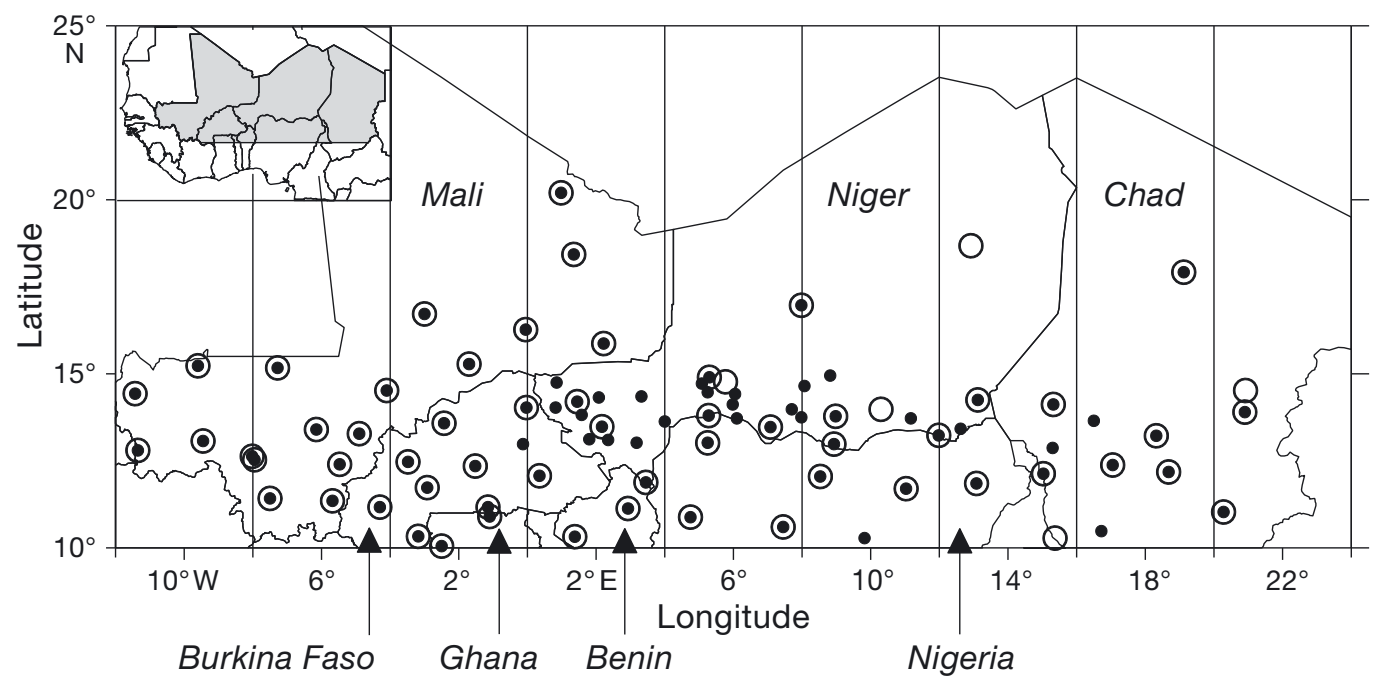

Fig. 4. Central Sudan-Sahel countries in West Africa, plus Chad, with location of stations for which daily meteorological data were analyzed. Small black dots locate rainfall stations used; unfilled circles are synoptic stations from which daily minimum temperature and daily maximum relative humidity were employed to obtain daily dew-point temperature; small black dots inside circles are for stations that made all 3 measurements. Vertical lines enclose $4^{\circ}$ longitude wide strips for which dekadal (10 d) Intertropical Front (ITF) latitude and total rainfall averages were obtained, as explained in Section 4.2. From Lélé \& Lamb (2010)

for 62 synoptic stations in the Sudan-Sahel zone (Fig. 4). These final data sets resulted from the acquisition of data for 83 stations from the DMNs/NWSs listed in the previous paragraph, and their extensive quality control.

The ITF-rainfall statistical analyses used 1974-2003 time series for the entire $10-20^{\circ} \mathrm{N}, 12^{\circ} \mathrm{W}-24^{\circ} \mathrm{E}$ study region of dekadal (10 d) and monthly (1) area-averaged rainfall totals and (2) area-averaged ITF latitudes. For rainfall, the area-averaging simply used raw station totals for each dekadal or monthly period and gave equal weight to each available station. Production of the areaaveraged ITF involved several steps: (1) dekadal averaging of station $T_{\mathrm{d}}$ values, (2) regionwide dekadal ITF delineation via a kriging interpolation of the $15^{\circ} \mathrm{C} T_{\mathrm{d}}$ isodrosotherm, (3) obtaining the dekadal mean ITF latitude for each $4^{\circ}$ longitude strip (Fig. 4), (4) averaging the nine $4^{\circ}$-strip values to give a regionwide mean dekadal ITF latitude, and (5) averaging the 3 dekadal ITF latitudes for each month to give a monthly mean value. Linear correlation and regression analyses and contingency tables established the strength of the rainfall dependency on ITF latitude, and indicated the predictive potential of that relationship via the predictability of the seasonal ITF advance and retreat.

\subsection{Diagnostic results}

Figs. $5 \& 6$ and Tables $2 \& 3$ document the strength of the ITF's contemporary control on rainfall using dekadal and monthly timescales. They reveal some important intraseasonal differences.
The relationship is positive for all months, indicating that rainfall increases with the extent of anomalous northward ITF penetration. However, the strength of the association has a pronounced seasonal cycle. It is very strong in the early (April-June; correlation magnitudes of 0.74 to 0.78 ) and late (October; 0.81 ) rainyseason months (Fig. 5), when the ITF is located further south and rainfall is much lower than during the intervening rainy-season core. These correlations are weakened only slightly when the seasonal cycles are removed from the time series.

However, this ITF latitude control on rainfall amount is lower during the July-September rainy-season core (Fig. 6; correlation magnitudes of 0.50 to 0.58 ). The association is weakest in August, when the ITF is furthest north, the southwest monsoon layer is thickest, and the resulting rainfall maximizes. This reduced ITF influence during July-September presumably stems from the thicker monsoon layer permitting a wider range of mesoscale dynamical processes to contribute to the development (or suppression) of the region's distinctive mesoscale weather systems. Note that the removal of the seasonal cycles from the time series did not reduce the August correlation, and that the weakened July and September correlations primarily resulted from variability at the very start (July, first dekad) and end (September, third dekad) of the rainy season core.

Tables 2 \& 3 employ a contingency approach to provide further insight into the concurrent positive ITF latitude-rainfall amount relationship on the monthly timescale. The 3 dekadal values of each parameter 

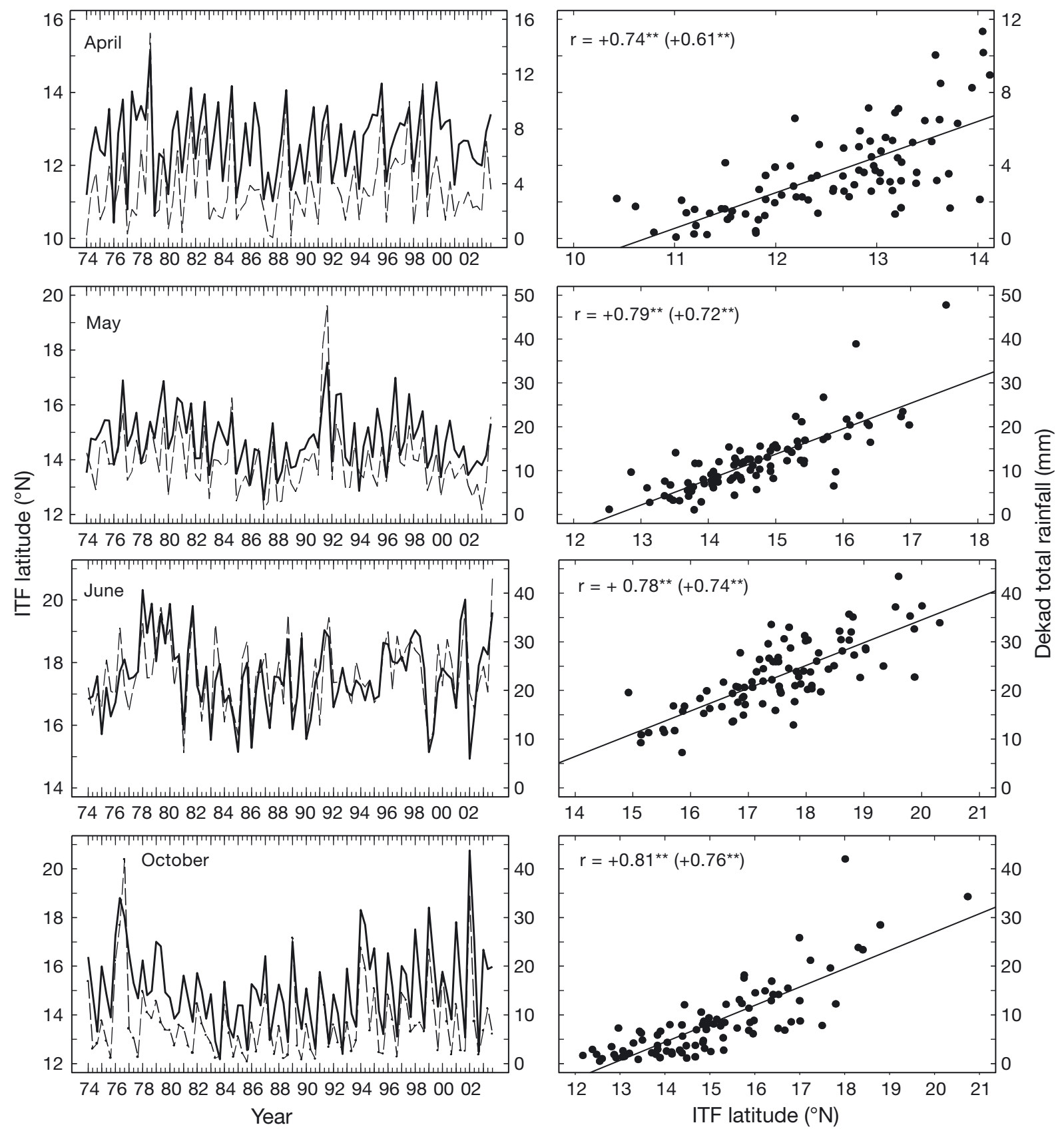

Fig. 5. Relationship between Intertropical Front (ITF) latitude and total rainfall for early (April-June) and late (October) rainyseason months in the West African Sudan-Sahel zone. Left panels: time series (1974-2003) of $10 \mathrm{~d}$ (dekad) averaged ITF latitude $\left({ }^{\circ} \mathrm{N}\right.$, solid line, left ordinate) and $10 \mathrm{~d}$ area averaged total rainfall ( $\mathrm{mm}$, broken line, right ordinate). Time series consist of 3 dekadal values per month for each year. Right panels: corresponding scatter diagrams and linear correlation coefficients, all of which are significant at the $1 \%$ level $\left({ }^{* *}\right)$ according to a 2-tailed Student's $t$-test (Wilks 2006, p. 131-135). Correlation coefficients in parentheses are for time series with seasonal cycles removed, where each dekadal value was the departure from the 1974-2003 dekadal mean. From Lélé \& Lamb (2010)

were averaged for each month, and then the resulting monthly means were ranked within the period 1974-2003 and stratified into terciles. The results in Table 2 emphasize further the strength of the associations for the early (April-June) and late (October) rainy season months. Particularly prominent are the high probabilities (64.44 to $71.11 \%$ ) that the ITF latitude tercile specifies the corresponding rainfall tercile (probability of detection $[\mathrm{PoD}]$ ), and the extremely low frequencies $(0.00$ to $6.66 \%)$ of an extreme-category rainfall amount coinciding with an opposite extremecategory ITF latitude (a two-category error [TCE]). 

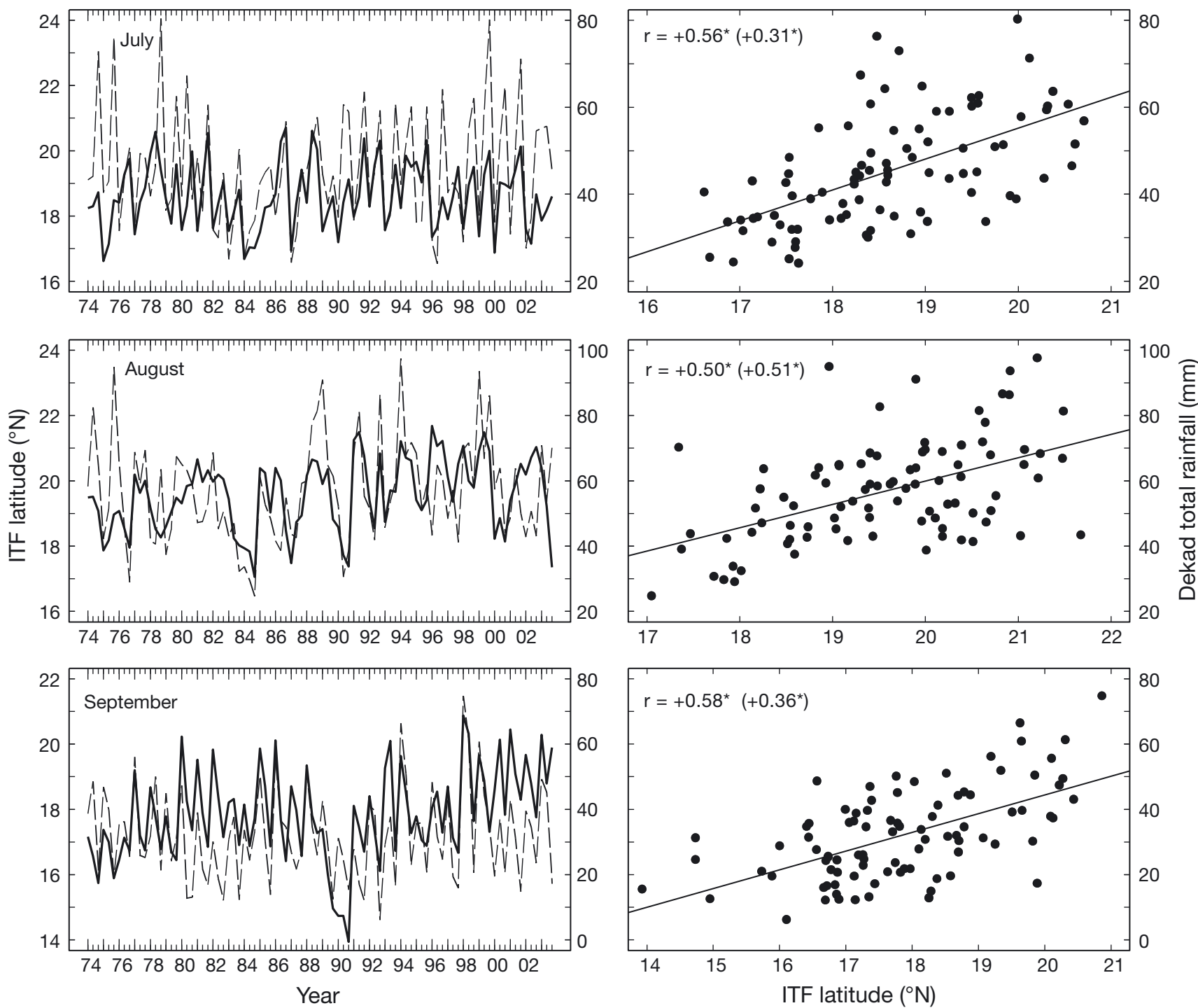

Fig. 6. Relationship between Intertropical Front (ITF) latitude and total rainfall for the core rainy-season months (July-September) in the West African Sudan-Sahel zone. Left panels: time series (1974-2003) of $10 \mathrm{~d}$ (dekad) averaged ITF latitude ( ${ }^{\circ} \mathrm{N}$, solid line, left ordinate) and $10 \mathrm{~d}$ area averaged total rainfall ( $\mathrm{mm}$, broken line, right ordinate). Time series consist of 3 dekadal values per month for each year. Right panels: corresponding scatter diagrams and linear correlation coefficients, all of which are significant at the $5 \%$ level $\left({ }^{*}\right.$ ) according to a 2-tailed Student's $t$-test (Wilks 2006, p. 131-135). Correlation coefficients in parentheses are for time series with seasonal cycles removed, where each dekadal value was the departure from the 1974-2003 dekadal mean. From Lélé \& Lamb (2010)

Equally important, however, is the further support that Table 3 provides for the existence of the positive ITF latitude-rainfall amount relationship during the July-September rainy-season core, despite the lower correlations obtained for this period (Fig. 6). The PoDs are in the 53.33 to $58.89 \%$ range, which is only about $10 \%$ lower than for April-June and October. For July and September, TCEs occurred for only 5.00 to $6.66 \%$ of months. However, TCEs were more frequent $(18.33 \%)$ for the maximum rainfall month of August, when the minimum correlation also occurred (Fig. 6).

\subsection{Seasonal prediction implications}

The moderate-to-strong concurrent ITF latituderainfall relationships prompted investigation of whether the early-season ITF latitude can be used to predict core and late-season Sudan-Sahel rainfall. That inquiry also involved documentation of the seasonal persistence of ITF latitude anomalies. Encouraging results are presented in Fig. 7 and Table 4.

There are 3 major outcomes of these predictability assessments. First, the early-season ITF latitude is a moderately consistent indicator of the ITF latitude and 
Table 2. Contingency table indicating concurrent tercile associations between monthly averages of dekadal (10 d) Intertropical Front (ITF) latitude and total rainfall values in Fig. 5 for early (April-June) and late (October) rainy-season months in the West African Sudan-Sahel zone. $\Delta$ South and $\Delta$ North: southern and northern ITF displacement terciles respectively. avg: average rainfall. PoD: probability of detection (of corresponding tercile values; bold). TCE: frequency of two-category (tercile values underlined) error. See Section 4.3 for further explanation. From Lélé \& Lamb (2010)

\begin{tabular}{|c|c|c|c|}
\hline $\begin{array}{l}\text { ITF } \\
\text { latitude }\end{array}$ & \multicolumn{2}{|c|}{$\begin{array}{l}\text { Total rainfall } \\
\text { Below avg. Near avg. Above avg. }\end{array}$} & Total \\
\hline \multicolumn{4}{|l|}{ April } \\
\hline$\Delta$ South & 23 & $\underline{0}$ & 30 \\
\hline Near avg. & 17 & 10 & 30 \\
\hline$\Delta$ North & 6 & 20 & 30 \\
\hline Total & 30 & 30 & 90 \\
\hline \multicolumn{4}{|c|}{$\mathrm{PoD}=66.66 \% ; \mathrm{TCE}=6.67 \%$} \\
\hline \multicolumn{4}{|l|}{ May } \\
\hline$\Delta$ South & 22 & $\underline{1}$ & 30 \\
\hline Near avg. & 18 & 5 & 30 \\
\hline$\Delta$ North & 5 & 24 & 30 \\
\hline Total & 30 & 30 & 90 \\
\hline \multicolumn{4}{|c|}{$\mathrm{PoD}=71.11 \% ; \mathrm{TCE}=3.33 \%$} \\
\hline \multicolumn{4}{|l|}{ June } \\
\hline$\Delta$ South & 24 & $\underline{1}$ & 30 \\
\hline Near avg. & 16 & 9 & 30 \\
\hline$\Delta$ North & $\underline{1}$ & 20 & 30 \\
\hline Total & $30 \quad 30$ & 30 & 90 \\
\hline \multicolumn{4}{|c|}{$\mathrm{PoD}=66.67 \% ; \mathrm{TCE}=3.33 \%$} \\
\hline \multicolumn{4}{|l|}{ October } \\
\hline$\Delta$ South & 21 & $\underline{0}$ & 30 \\
\hline Near avg. & 14 & 7 & 30 \\
\hline$\Delta$ North & 7 & 23 & 30 \\
\hline Total & 30 & 30 & 90 \\
\hline \multicolumn{4}{|c|}{$\mathrm{PoD}=64.44 \% ; \mathrm{TCE}=0.00 \%$} \\
\hline
\end{tabular}

associated rainfall in the first core rainy season month of July. In particular, Fig. 7 shows that the April ITF latitude has a correlation of +0.55 with the July ITF latitude and +0.53 with rainfall, which is surprisingly close to the concurrent July ITF latitude-rainfall correlation (+0.56; Fig. 6). Table 4 indicates that the associated PoD of the April ITF latitude tercile specifying the corresponding July ITF latitude tercile is $48.89 \%$, and $42.22 \%$ for rainfall, and the likelihood of TCEs is only $6.67 \%$ for ITF latitude and $10.00 \%$ for rainfall. Most of these values also are close to their concurrent July ITF latitude-rainfall counterparts of 58.89 and $5.00 \%$ (Table 3). Interestingly, these July predictability results based on the April ITF latitude are slightly stronger than those derived from the more immediately preceding May and June ITF latitudes (e.g. Fig. 7).

Thus, April ITF latitude and associated rainfall anomalies tend to persist through July. However, such persistence generally is not sustained into the peak rainy season month of August, which is the second
Table 3. Contingency table indicating concurrent tercile associations between monthly averages of dekadal (10 d) ITF latitude and total rainfall values in Fig. 6 for the core rainy-season months (July-September) in the West African Sudan-Sahel zone. See Table 2 legend for other details. From Lélé \& Lamb (2010)

\begin{tabular}{|c|c|c|c|}
\hline $\begin{array}{l}\text { ITF } \\
\text { latitude }\end{array}$ & $\begin{array}{l}\text { Total rair } \\
\text { Below avg. Near av }\end{array}$ & ve avg. & Total \\
\hline \multicolumn{4}{|l|}{ July } \\
\hline$\Delta$ South & 21 & 1 & 30 \\
\hline Near avg. & 13 & 10 & 30 \\
\hline$\Delta$ North & 9 & 19 & 30 \\
\hline Total & $30 \quad 30$ & 30 & 90 \\
\hline \multicolumn{4}{|c|}{$\mathrm{PoD}=58.89 \% ; \mathrm{TCE}=5.00 \%$} \\
\hline \multicolumn{4}{|l|}{ August } \\
\hline$\Delta$ South & 18 & $\underline{4}$ & 30 \\
\hline Near avg. & 15 & 10 & 30 \\
\hline$\Delta$ North & 7 & 16 & 30 \\
\hline Total & $30 \quad 30$ & 30 & 90 \\
\hline \multicolumn{4}{|c|}{$\mathrm{PoD}=54.44 \% ; \mathrm{TCE}=18.33 \%$} \\
\hline \multicolumn{4}{|l|}{ September } \\
\hline$\Delta$ South & 11 & $\underline{2}$ & 30 \\
\hline Near avg. & 11 & $\overline{8}$ & 30 \\
\hline$\Delta$ North & 8 & 20 & 30 \\
\hline Total & $30 \quad 30$ & 30 & 90 \\
\hline \multicolumn{4}{|c|}{$\mathrm{PoD}=53.33 \% ; \mathrm{TCE}=6.67 \%$} \\
\hline
\end{tabular}

principal outcome of this predictability assessment. The correlations of August ITF latitude and rainfall with the ITF latitude during preceding months all are near zero (Fig. 7). Furthermore, Table 4 indicates that the PoDs of the April ITF latitude specifying the corresponding August ITF latitude (31.11\%) and rainfall $(33.56 \%)$ are around the climatological value (33.33\%), with TCEs occurring $40.00 \%$ and $36.67 \%$ of the time, respectively. In fact, these PoDs (TCEs) are slightly smaller (larger) than equivalents computed using the opposite matrix diagonals (extreme terciles) in Table 4. Similar PoD and TCE percentages were obtained when the May ITF latitude tercile was used to predict the August ITF latitude and rainfall (not shown). So, not only is the concurrent ITF latitude control on rainfall weaker for August than for all earlier months, but the August ITF latitude and rainfall often are uncoupled from the ITF latitude anomaly sustained to that point in the rainy season evolution. This further uniqueness of August is another finding that invites numerical model experimentation.

The third major outcome of this predictability assessment is that the independence of the August ITF latitude and rainfall from the early-season ITF latitude often is part of a July-August-September transition to the opposite ITF latitude anomaly. This transition reflects a moderate tendency for the ITF to retreat southward early (late) in seasons when it advanced northward early (late). For example, Fig. 7 shows that 


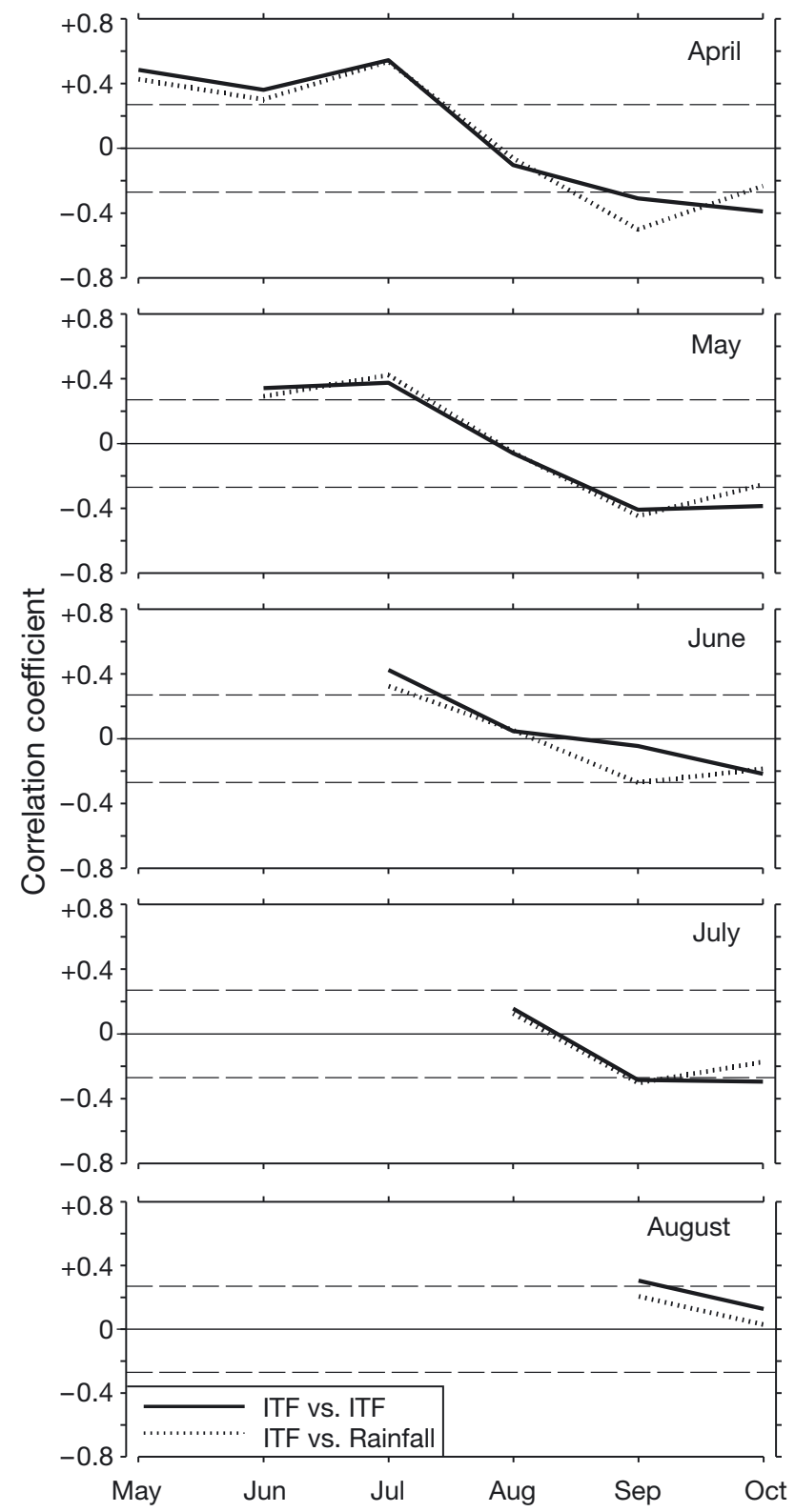

Fig. 7. Seasonal persistence of Intertropical Front (ITF) latitude and its control on rainfall for the West African SudanSahel zone. Curves give linear correlation between average ITF latitude for the month indicated (April-August) and average ITF latitude (-) and mean total rainfall (.......) during subsequent months. The $1 \%$ significance levels for correlation coefficients according to a 2-tailed Student's $t$-test are shown (— - ) (Wilks 2006, p. 131-135). From Lélé \& Lamb (2010)

the correlation of the April ITF latitude with (1) the September ITF latitude is -0.31 , and -0.50 with rainfall, and (2) the October ITF latitude is -0.40 , and -0.23 with rainfall. Consistent with this situation, the PoDs of the April ITF latitude tercile specifying the corresponding September and October ITF latitude terciles are only $18.89 \%$ (16.67\% for rainfall) and $22.22 \%$ (24.44\% for rainfall), respectively, and the associated
TCEs are $48.33 \%$ (55.00\% for rainfall) and 50.00\% $(43.33 \%$ for rainfall) (Table 4$)$. The July-AugustSeptember transition to the opposite ITF latitude anomaly is sufficiently frequent that use of the April ITF latitude to predict September and October ITF latitudes and rainfalls gave much larger PoD-equivalents (38.88 to $46.67 \%$ ) and much smaller TCE-equivalents (10.00 to $21.67 \%$ ) when they were computed using the opposite matrix diagonals and opposite extreme terciles, respectively, in Table 4. The August results in Table 4 show a slight tendency for this transition to begin in that month. Thus, taking into account this mid-season ITF latitude anomaly transition, the April ITF latitude specification of the September-October ITF latitude and rainfall is almost as consistent as that for July (Table 4).

An additional development effort is required to underpin the 'transition to operations' of the encouraging 'local' seasonal prediction potential offered by the April ITF latitude anomaly. On a much larger scale, associations of Sudan-Sahel seasonal rainfall totals with basin- and global-scale sea surface temperature anomalies have been established strongly on interannual-to-multidecadal timescales (e.g. Lamb 1978a,b, Folland et al. 1986, Palmer 1986, Lamb \& Peppler 1992, Palmer et al. 1992, Ward 1998, Giannini et al. 2003, Hoerling et al. 2006, Nicholson \& Webster 2007). Bridging the gap between this local and ocean basinto-global understanding must involve documenting the large-scale teleconnection and regional-scale circulation processes that influence the April ITF latitude and the persistence of ITF latitude anomalies throughout the rainy season.

\subsection{Professional-development context and assessment}

Following the pattern in Section 3.5, we now assess the above research and development (Sections 4.1 to 4.4) and its potential applications in the context of the 3-prerequisite professional-development framework proposed for seasonal climate prediction at the start of Section 2.

The quantification of the role of the ITF latitude for rainfall addressed the first prerequisite (Section 2.1) in the seasonal climate prediction framework, but somewhat indirectly and incompletely. This identification of the impact of climate variability addressed the effects of one meteorological parameter (ITF latitude) on another meteorological parameter (rainfall, via water vapor association) that, in turn, is considered to have important societal impacts (public health, agriculture, water resources), as opposed to linking either of these meteorological parameters directly to societal impacts. Establishment of the ITF latitude-rainfall relationship 
Table 4. Contingency table indicating predictive tercile associations between April ITF latitude and ITF latitude and total rainfall in subsequent months in the West African Sudan-Sahel zone. PoD and TCE values in parentheses for August-October were computed using opposite matrix diagonals (bold) and opposite extreme terciles (underlined), respectively. See Table 2 legend for further details. From Lélé \& Lamb (2010)

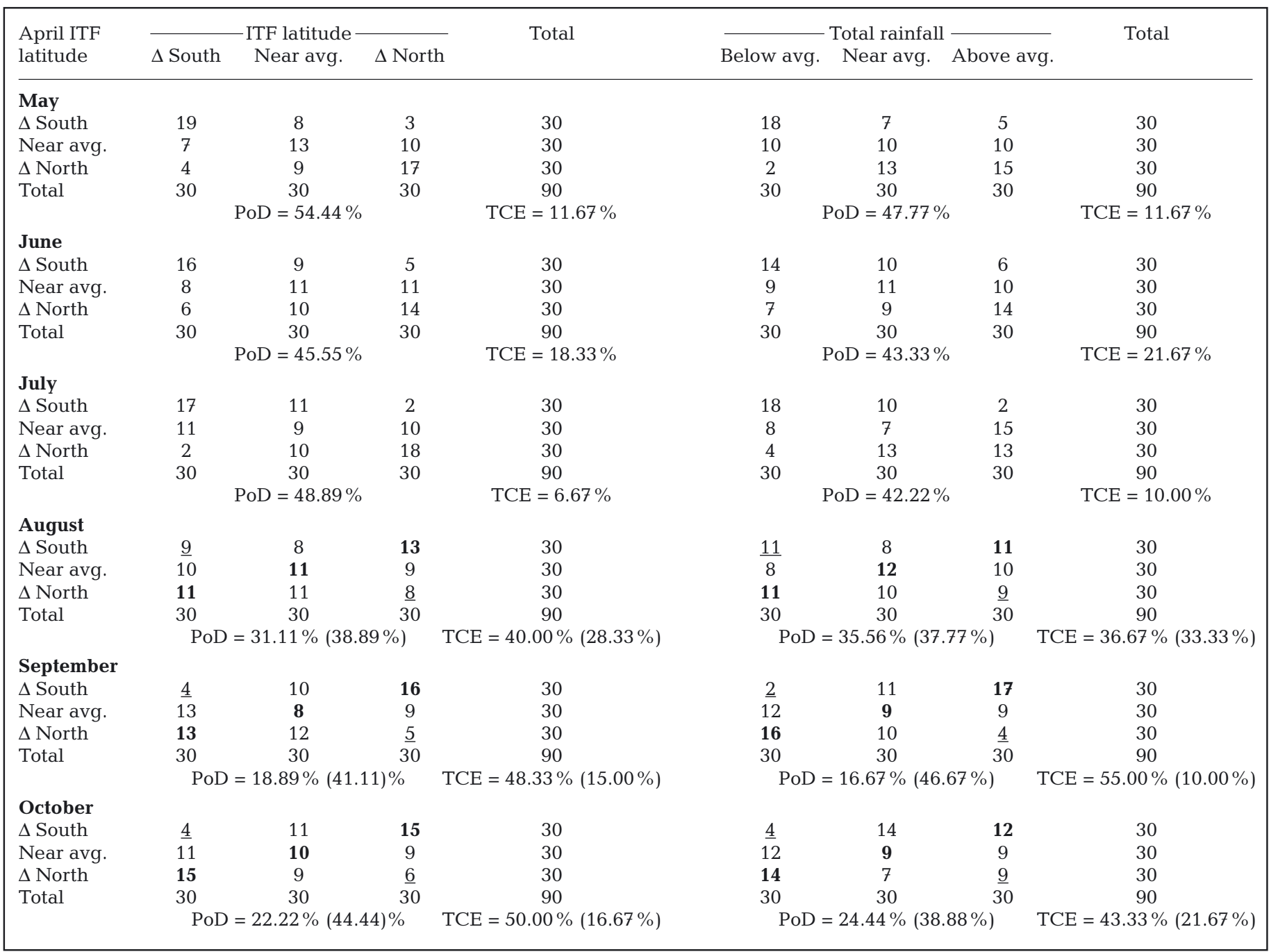

was permitted by the availability of appropriate sets of daily meteorological data (rainfall, minimum temperature, maximum relative humidity). The development of those data sets required considerable effort by personnel from outside the NMHSs (M. V. K. Sivakumar at ICRISAT-Sahel; M. A. Bell and M. I. Lélé at The University of Oklahoma) and added considerable value to the raw data obtained from the NMHS archives. Related professional-development challenges for NMHSs involve increasing their appreciation of the requirements of research quality data sets and contributing more substantially to their creation.

Because the above analysis (Sections 4.1 to 4.4 ) was not extended to the direct impact of either the ITF or rainfall on disease incidence and transmission, agricultural production, or water resource levels, the first pre- requisite (Section 2.1) was not addressed comprehensively. However, the strength of the identified ITF control on rainfall (including its predictability) offers encouragement for the development of the impacts data sets (under the first prerequisite) and management decision conceptualization and modeling (the second prerequisite, Section 2.2) needed to extend the analysis to vital societal considerations. There has been some important initial activity in these areas for the Sudan-Sahel zone in recent years, stimulated in part by the African Monsoon Multidisciplinary Analysis (AMMA) program (Redelsperger et al. 2006; www.amma-international.org).

For agriculture, the aforementioned availability of basic production data sets (Section 2.1; e.g. Dibi Kanagh 2010) is permitting their refinement for investigation of important specific challenges, such as exploring the 
potential feasibility of and interest in weather-indexed drought insurance for Burkina Faso farmers (Berg et al. 2009). The latter study included modeling of the type advocated here, as did (more comprehensively) Sultan et al.'s (2010) encouraging preliminary assessment of the potential economic value of seasonal forecasts for semi-arid Senegal. The Sultan et al. (2010) investigation used an integrated 'archetypal bioeconomic model of a small-holder farm' that fundamentally was a simplified Senegalese version of the schematic representation in Fig. 1. For malaria prediction, the integrated modeling approach has proven successful for Botswana on the seasonal scale (Jones \& Morse 2010) and now is being applied to the Sahel (A. P. Morse pers. comm.), for which promising shorter-term results already have been obtained (Cui et al. 2009, Caminade et al. 2011). Progress also is being made on water resource modeling for the Sudan-Sahel zone, as documented in Lebel et al. (2009). Further development of these efforts, and especially their all-important integration in the present context, will require full awareness within and information exchanges between NMHSs, other government agencies, regional organizations such as AGRHYMET and the African Centre of Meteorological Applications for Development (ACMAD), and NGOs.

Concerning the third prerequisite (Section 2.3), the recent and expanding ITF and impacts-related research summarized above (Sections 4.1 to 4.4 ) has the potential to provide a comprehensive basis for focusing the development of Sudan-Sahel seasonal climate predictions that have maximum societal value. Unlike for the US winter temperature-natural gas consumption case considered in Section 3.5, all of this effort should occur in the public domain without restriction. The strong societal need and desire for such predictions was captured by Tarhule \& Lamb (2003) in a 4-nation survey that encompassed village, government agency, and NGO levels. Their results also documented forcefully the failure to date to parlay enhanced climate system understanding into better societal adaptation to intraseasonal-to-seasonalto-interannual rainfall variability. However, increasing the societal utility of seasonal climate predictions invariably is technically challenging, as Section 3.4 noted for the US energy industry and Hansen (2002) and Hansen et al. (2006) have demonstrated for agriculture in general. For the Sudan-Sahel zone, the wide-ranging professional development already outlined will be required to improve the current situation (e.g. Mason \& Chidzambwa 2008, Sultan et al. 2009).

\section{SUMMARY AND CONCLUSIONS}

The increasing emphasis worldwide on the need to expand the provision of climate services most certainly will include greater demand for seasonal climate predictions. Furthermore, such predictions should be tailored as closely as possible to the requirements of society, as opposed to resulting only from the unguided curiosity and initiative of climate scientists. It is from this perspective that the present paper focused on the research basis for seasonal climate prediction. Particular emphasis was placed on the broad professional development that is needed at the national and multinational regional levels to produce societal benefits and thus advance the climate services initiative.

The approach used involved a 3-step interdisciplinary framework that previously had been proposed to maximize the societal value of seasonal climate prediction schemes. Those steps (termed prerequisites) were considered to be demanding and reasonably sequential. They advanced from (1) identification of the human activities most impacted by climate variability, to (2) determination of how affected regional economies can adjust or change to capitalize on the availability of skillful climate predictions, to (3) the use of results from the required interdisciplinary research to develop climate prediction schemes that have maximum societal value.

Consideration of these prerequisites identified wideranging needs for professional development, particularly in emerging nations. Essential for the accomplishment of all 3 prerequisites will be interdisciplinary thinking, cooperation, and collaboration that likely exceeds the traditional practices of many NMHSs. Pursuit of the first prerequisite will require the development of both sizeable daily meteorological data sets and diverse sets of impacts data for the affected sectors (agricultural production, water resource levels, human disease incidence and transmission, energy consumption), along with joint statistical analysis. Conceptualization and modeling of the management decisions involved in these socioeconomic activities were suggested to be central to addressing the second prerequisite, and to require the 2-way coupling of a biological or physical process model embedded within an economic model. To satisfy the third prerequisite, the climate research community was urged to keep fully abreast of key developments in the interdisciplinary research areas that have implications for climate prediction design. The strong El Niño control on US winter precipitation was used to emphasize the potential for impact-related guidance to maximize seasonal prediction value.

This theme was developed further by emphasizing the methodologies and re-assessing the results for 2 recent strongly contrasting climate research projects. Those studies focused on opposite ends of the global continuum of socioeconomic development: temperature control on US residential natural gas consumption, 
and West African ITF control on Sudan-Sahel rainfall and (implicitly) socioeconomic activity. Despite their contrasting foci, these studies were found to reinforce the following professional development and related requirements: availability of large sets of daily meteorological data permitted quantification of impact-oriented indices; the equally important impacts data sets were less available but becoming more developed; management decision conceptualization and modeling either were conducted confidentially within the private sector (USA) or were undergoing encouraging initial development (West Africa); and considerable potential exists for the coincidence of important seasonal prediction skill with strong societal needs. Only through appropriate professional development will such potential be realized, for these regions and elsewhere, and thus help enhance climate services.

Acknowledgements. P.J.L. appreciated the invitation to present a paper on this topic to the WMO CCl Technical Conference on Changing Climate and Demands for Climate Services for Sustainable Development (Antalya, Turkey, February 16-18, 2010). The research reported here used data sets developed by M. Bell, M. Richman, and M. V. K. Sivakumar. The ideas developed in the present paper were shaped by many years of interactions with a considerable number of helpful people from several disciplines, including $\mathrm{M}$. S. Boulahya, T. Karl, J. Lawrimore, R. Livezey, J. Mjelde, the late D. O'Brien, S. Sonka, and A. Tarhule. Interactions with W. Higgins, S. Mason, and N. Ward were most helpful. The paper is a USA contribution to the multinational African Monsoon Multidisciplinary Analysis (AMMA) Project. Funding was provided by NOAA (NESDIS National Climatic Data Center, NWS International Activities Office) through Grant NA17RJ1227. The expert production of the manuscript at CIMMS by L. Byrd was appreciated greatly.

\section{LITERATURE CITED}

Barnston AG, Li S, Mason SJ, Dewitt DG, Goddard L, Gong X (2010) Verification of the first 11 years of IRI's seasonal climate forecasts. J Appl Meteorol Climatol 49:493-520

$>$ Berg A, Quirion P, Sultan B (2009) Weather-index drought insurance in Burkina Faso: assessment of its potential interest to farmers. Weather Clim Soc 1:71-84

Caminade C, Ndione JA, Kebe CMF, Jones A and others (2011) Mapping Rift Valley fever and malaria risk over West Africa using climatic indicators. Atmos Sci Lett 12: 96-103

Changnon SA Jr (ed) (2000) El Niño 1997-98: the climate event of the century. Oxford University Press, Oxford

- Crane TA, Roncoli C, Paz J, Breuer N, Broad K, Ingram KT, Hoogenboom G (2010) Forecast skill and farmers' skills: seasonal climate forecasts and agricultural risk management in the southeastern United States. Weather Clim Soc 2:44-59

Cui X, Parker DJ, Morse AP (2009) The drying out of soil moisture following rainfall in a numerical weather prediction model and implications for malaria prediction in West Africa. Weather Forecast 24:1549-1557

Dibi Kanagh PA (2010) Rainfall and agriculture in central
West Africa since 1930. LAP Lambert Academic Publishing, Saarbrücken

Folland CK, Palmer TN, Parker DE (1986) Sahel rainfall and worldwide sea surface temperatures. Nature 320:602-607

Giannini A, Saravanan R, Chang P (2003) Oceanic forcing of Sahel rainfall on interannual to decadal time scales. Science 302:1027-1030

Hansen JW (2002) Realizing the potential benefits of climate prediction to agriculture: issues, approaches, challenges. Agric Syst 74:309-330

> Hansen JW, Challinor A, Ines A, Wheeler T, Moron V (2006) Translating climate forecasts into agricultural terms: advances and challenges. Clim Res 33:27-41

Hill HSJ, Mjelde JW, Rosenthal W, Lamb PJ (1999) The potential impacts of the use of Southern Oscillation information on the Texas aggregate sorghum production. J Clim 12: $519-530$

Hill HSJ, Mjelde JW, Love HA, Rubas DJ, Fuller SW, Rosenthal WD, Hammer GL (2004) Implications of seasonal climate forecasts on world wheat trade: a stochastic, dynamic analysis. Can J Agric Econ 52:289-312

> Hoerling MP, Hurrell JW, Eischeid J (2006) Detection and attribution of twentieth century northern and southern Africa monsoon change. J Clim 19:3989-4008

Ingram KT, Roncolli MC, Kirshen PH (2002) Opportunities and constraints for farmers of West Africa to use seasonal precipitation forecasts with Burkina Faso as a case study. Agric Syst 74:331-349

Jones AE, Morse AP (2010) Application and validation of a seasonal ensemble prediction system using a dynamic malaria model. J Clim 23:4202-4215

> Kiladis GN, Diaz HF (1989) Global climate anomalies associated with the Southern Oscillation. J Clim 2:1069-1090

> Lamb PJ (1978a) Large-scale tropical Atlantic surface circulation patterns associated with Subsaharan weather anomalies. Tellus 30:240-251

> Lamb PJ (1978b) Case studies of tropical Atlantic surface circulation patterns during recent sub-Saharan weather anomalies: 1967 and 1968. Mon Weather Rev 106:482-491

Lamb PJ (1981) Do we know what we should be trying to forecast_climatically? Bull Am Meteorol Soc 62:1000-1001

> Lamb PJ, Changnon SA Jr (1981) On the 'best' temperature and precipitation normals: the Illinois situation. J Appl Meteorol 20:1383-1390

> Lamb PJ, Peppler RA (1992) Further case studies of tropical Atlantic surface atmospheric and oceanic patterns associated with sub-Saharan drought. J Clim 5:476-488

Lebel T, Cappelaere B, Vieux B, Galle S, Hanan N, Kergoat L, Levis S (eds) (2009) Surface processes and water cycle in West Africa, studied from AMMA-CATCH observing system. J Hydrol 375(1-2):1-295

> Lélé MI, Lamb PJ (2010) Variability of the Intertropical Front (ITF) and rainfall over West African Sudan-Sahel zone. J Clim 23:3984-4004

Livezey RE (1990) Variability of skill of long-range forecasts and implications for their use and value. Bull Am Meteorol Soc 71:300-309

> Livezey RE, Timofeyeva MM (2008) The first decade of longlead U.S. seasonal forecasts. Bull Am Meteorol Soc 89: 843-854

Livezey RE, Masutani M, Leetmaa A, Rui H, Ji M, Kumar A (1997) Teleconnective response of the Pacific-North American region atmosphere to large central equatorial Pacific SST anomalies. J Clim 10:1787-1820

Mason S, Chidzambwa S (2008) Verification of African RCOF forecasts. Tech Rep 09-02. International Research Institute for Climate and Society, Columbia University, New York, NY 
Mazzocco MA, Mjelde JW, Sonka ST, Lamb PJ, Hollinger SE (1992) Using hierarchical systems aggregation to model the value of information in agricultural systems: an application to climate forecast information. Agric Syst 40:393-412

Mjelde JW, Sonka ST, Dixon BL, Lamb PJ (1988) Valuing forecast characteristics in a dynamical agricultural production system. Am J Agric Econ 70:674-684

Mjelde JW, Peel DS, Sonka ST, Lamb PJ (1993) Characteristics of climate forecast quality: implications for economic value to Midwestern corn producers. J Clim 6:2175-2187

Mjelde JW, Thompson TN, Nixon CJ, Lamb PJ (1997) Utilizing a farm-level decision model to help prioritize future climate prediction research needs. Meteorol Appl 4:161-170

Montroy DL (1997) Linear relation of central and eastern North American precipitation to tropical Pacific sea surface temperature anomalies. J Clim 10:541-558

Montroy DL, Richman MB, Lamb PJ (1998) Observed nonlinearities of monthly teleconnections between tropical Pacific sea surface temperature anomalies and central and eastern North American precipitation. J Clim 11:1812-1835

National Academy of Public Administration (2010) Building strong for tomorrow: NOAA Climate Service. A report by a panel of the National Academy of Public Administration for the US Department of Commerce, National Oceanic and Atmospheric Administration, and the US Congress. National Academy of Public Administration, Washington, DC

> Nicholson SE, Webster PJ (2007) A physical basis for the interannual variability of rainfall in the Sahel. Q J R Meteorol Soc 133:2065-2084

O'Lenic EA, Unger DA, Halpert MS, Pelman KS (2008) Developments in operational long-range climate prediction at CPC. Weather Forecast 23:496-515

Palmer TN (1986) The influence of the Atlantic, Pacific, and Indian Oceans on Sahel rainfall. Nature 322:251-253

Palmer TN, Branković C, Viterbo P, Miller MJ (1992) Modeling interannual variations of summer monsoons. J Clim 322:251-253

Rasmusson EA, Carpenter TH (1982) Variations in tropical sea surface temperature and surface wind fields associated with the Southern Oscillation/El Niño. Mon Weather Rev 110:354-384

Redelsperger JL, Thorncroft CD, Diedhiou A, Lebel T, Parker DJ, Polcher J (2006) African Monsoon Multidisciplinary Analysis: an international research project and field campaign. Bull Am Meteorol Soc 87:1739-1746

Ropelewski CF, Halpert MS (1986) North American precipitation and temperature patterns associated with the El Niño/ Southern Oscillation. Mon Weather Rev 114:2352-2362

Ropelewski CF, Halpert MS (1987) Global and regional scale precipitation patterns associated with the El Niño/Southern Oscillation. Mon Weather Rev 115:1606-1626

Ross T, Lott N, McCown S, Quinn D (1998) The El Niño

Submitted: June 8, 2010; Accepted: October 18, 2010 winter of '97-'98. NCDC Tech Rep No. 98-02. National Oceanic and Atmospheric Administration, Washington, DC $>$ Rubas DJ, Mjelde JW, Love HA, Rosenthal WD (2008) How adaption rates, timing, and ceilings affect the value of ENSO-based climate forecasts. Clim Change 86:235-256

Sherrick BJ, Sonka ST, Lamb PJ, Mazzocco MA (2000) Decision-maker expectations and the value of climate production information. Meteorol Appl 7:377-386

Skinner BD, Changnon D, Richman MB, Lamb PJ (1999) Damaging weather conditions in the United States: a selection of data quality and monitoring issues. Clim Change 42:69-87

Sonka ST, Lamb PJ (1987) On climate change and economic analysis. Clim Change 11:291-311

> Sonka ST, Lamb PJ, Changnon SA Jr, Wiboonpongse A (1982) Can climate forecasts for the growing season be valuable to crop producers: some general considerations and an Illinois pilot study. J Appl Meteorol 21:471-476

Sonka ST, Mjelde JW, Lamb PJ, Hollinger SE, Dixon BL (1987) Valuing climate forecast information. J Clim Appl Meteorol 26:1080-1091

Sultan B, Janicot S, Correia C (2009) Medium lead-time predictability of intraseasonal variability of rainfall in West Africa. Weather Forecast 24:767-784

Sultan B, Barbier B, Fortilus J, Mbaye SM, Leclerc G (2010) Estimating the potential economic value of seasonal forecasts in West Africa: a long-term ex-ante assessment in Senegal. Weather Clim Soc 2:69-87

Tarhule A, Lamb PJ (2003) Climate research and seasonal forecasting for West Africans: perceptions, dissemination, and use. Bull Am Meteorol Soc 84:1741-1759

Tarhule A, Saley-Bana Z, Lamb PJ (2009) Rainwatch: a prototype GIS for daily and seasonal rainfall monitoring and visualization in West Africa. Bull Am Meteorol Soc 90: $1607-1614$

> Timmer RP, Lamb PJ (2007) Relations between temperature and residential natural gas consumption in the central and eastern United States. J Appl Meteorol Climatol 46:1993-2013

Ward MN (1998) Diagnosis and short-lead time prediction of summer rainfall in tropical North Africa on interannual and multidecadal timescales. J Clim 11:3167-3191

Ward MN, Folland CK (1991) Prediction of seasonal rainfall in the north Nordeste of Brazil using eigenvectors of seasurface temperature. Int J Climatol 11:711-743

Wilks DS (2006) Statistical methods in atmospheric sciences, 2nd edn. Elsevier, Amsterdam

WMO (1996) Exchanging meteorological data: guidelines on relationships in commercial meteorological activities: WMO policy and practice. WMO No. 837. WMO, Geneva

WMO (2009) World Climate Conference-3-and after: a global framework for climate services? World Climate News No. 35. WMO, Geneva

Proofs received from author(s): March 14, 2011 